Florida International University

FIU Digital Commons

FIU Electronic Theses and Dissertations

University Graduate School

7-24-1995

\title{
Perceptions of beginning teachers in Florida regarding their preparation as it relates to the Florida essential generic competencies
}

María Antonieta Bilbao

Florida International University

DOI: $10.25148 /$ etd.FI14051152

Follow this and additional works at: https://digitalcommons.fiu.edu/etd

Part of the Higher Education Commons

\section{Recommended Citation}

Bilbao, María Antonieta, "Perceptions of beginning teachers in Florida regarding their preparation as it relates to the Florida essential generic competencies" (1995). FIU Electronic Theses and Dissertations. 1677.

https://digitalcommons.fiu.edu/etd/1677

This work is brought to you for free and open access by the University Graduate School at FIU Digital Commons. It has been accepted for inclusion in FIU Electronic Theses and Dissertations by an authorized administrator of FIU Digital Commons. For more information, please contact dcc@fiu.edu. 
FLORIDA INTERNATIONAL UNIVERSITY

Miami, Florida

PERCEPTIONS OF BEGINNING TEACHERS IN FLORIDA REGARDING THEIR PREPARATION AS IT RELATES TO THE FLORIDA ESSENTIAL GENERIC COMPETENCIES

A dissertation submitted in partial satisfaction of the requirements for the degree of DOCTOR OF EDUCATION

IN ADULT EDUCATION AND HUMAN RESOURCES DEVELOPMENT

by

Maria Antonieta Bilbao 
To: Dean I. Ira Goldenberg, College of Education

This dissertation, written by Maria Antonieta Bilbao, and entitled Perceptions of Beginning Teachers in Florida Regarding Their Preparation as it Relates to the Florida Essential Generic Competencies, having been approved in respect to style and intellectual content, is referred to you for judgement.

We have read this dissertation and recommend that it be approved.

Erskine S. Dottin

Lorraine R. Gay

Paul A. Rendulic

Douglas H. Smith, Major Professor

Date of Defense: July 24, 1995

The dissertation of Maria Antonieta Bilbao is approved.

Dean I. Ira Goldenberg

College of Education

Dean Richard L. Campbell

Dean of Graduate Studies

Florida International University, 1995 
(C) Copyright 1995 by Maria Antonieta Bilbao

All rights reserved 
Without the support of a loving family this work would not be completed. I dedicate it with all my heart to my husband Jorge, my daughter Katerina, my mother Dora, Nena, my sister Maria Eugenia, nephews Christian and Anthony, and particularly my father, Antonio Benjamin, who always taught me that education was the most precious possession in life.

Thank you for the time I took away from all of you. 


\section{ACKNOWLEDGMENTS}

There have been many who in one way or another have contributed to the completion of this project. Thanks to the support and encouragement of professors, colleagues, friends and family the dream became a reality.

I would like to express appreciation to the members of my committee: Dr. Erskine Dottin for sharing his expertise on the topic, Dr. Lorraine Gay whose encouragement and invaluable advice helped me to keep moving toward my goal, to my major professor, Dr. Douglas Smith for his support and assistance to complete my degree. A special note of appreciation is extended to Dr. Paul Rendulic, who is one of those special human beings who crossed my path to very patiently guide me through statistics, research, and the completion of this study.

Among my colleagues I must acknowledge Dean Ira Goldenberg for his constant support and faith in me during the past years, Associate Dean Rob Vos, for being my source of energy and inspiration, Assistant Dean Carmen Mendez for helping me keep my sense of humor, and Dr. Martin Hamburger for his willingness to provide assistance when most needed. Above all, my thanks to Dr. Judy Wilkerson who graciously shared her work which enabled me to continue the research she had begun.

Among the friends who have been a source of support during the completion of this project are Angie Rodriguez, Yolanda Nufer, Nena Zabaleta and Lily Perez. The greatest support and encouragement I owe to my friend Dr. Tony Machado, whose tenacity and example were the guiding light at times of discouragement. 
A special acknowledgment and debt of gratitude needs to go to an individual that plays many roles in my life. A friend, colleague, and confidant who has always been by my side for every major project in my career in higher education, Marilyn Vinson. She has always been a steady source of support and motivation. Thank you for transforming those illegible handwritten notes into this beautiful text.

And then there are those for whom words of thanks have not been invented, my husband Jorge and daughter Katerina.... 


\author{
ABSTRACT OF THE DISSERTATION \\ PERCEPTIONS OF BEGINNING TEACHERS IN FLORIDA REGARDING \\ THEIR PREPARATION AS IT RELATES TO THE FLORIDA \\ ESSENTIAL GENERIC COMPETENCIES \\ by \\ Maria Antonieta Bilbao \\ Florida International University, 1995 \\ Professor Douglas H. Smith, Major Professor
}

The purpose of the study is to investigate how beginning teachers in the state of Florida perceive their preparation to demonstrate the 27 Florida Essential Generic Competencies.

The basic research question of this study was: How do beginning teachers perceive their level of preparation regarding their implementation of the Florida Essential Generic Competencies? This study identified and categorized the perceived degree of preparation for each of the competencies. Also, elementary, middle, and high school beginning teachers were compared to find significant differences and similarities in their perception of their preparation. A comparison was also done for graduates from in-state versus out-of-state and private versus public institutions.

A survey developed in collaboration with the Department of Education, Florida State University, members of the Professional Orientation Program (POP) Coordinators, 
and the Project Director of Program Review in the College of Education at the University of South Florida, was sent to 5,076 beginning teachers. A total of 1,995 returned the survey in February of 1993. The Multivariate Analysis of Variance (MANOVA) procedure was used $($ Alpha $=.05)$. Statistical analysis of the data involved a comparison of the different groups of beginning teachers by school level and kind of graduating institutions. The dependent variables analyzed were the responses to all items representing the generic competencies.

The study identified and categorized the degree of preparation for each competency. The competencies receiving the lowest ratings for degree of preparation were: integrate computers in instruction; manage situations involving child abuse and/or neglect; severe emotional stress; alcohol and drug abuse.

The Wilkes lambda and the Hotellings multivariate tests of significance were used to examine the differences among the groups. The competency items were further analyzed by a univariate F test. Results indicated that: (1) significant differences were found in nine competency items in which elementary teachers felt better prepared than middle and high school beginning teachers, (2) graduates from a Florida teacher education program felt they were better prepared in demonstrating the competencies than those from out-of-state schools, and (3) no significant difference was found in the perceptions of those who graduated from public versus private institutions.

Based on the findings of this study, the following recommendations are made: (1) Florida's institutions responsible for teacher preparation programs need to focus on those 
competencies receiving the lowest ratings, (2) Districts should provide an orientation program for out-of-state beginning teachers, and (3) The survey instrument should be used annually to evaluate teacher education programs. 


\section{TABLE OF CONTENTS}

CHAPTER

PAGE

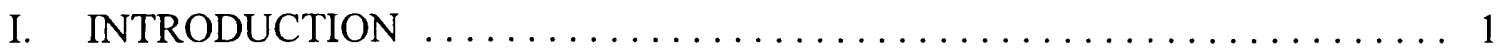

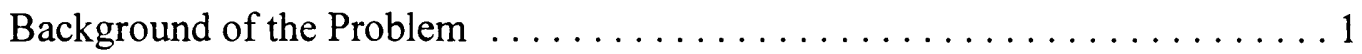

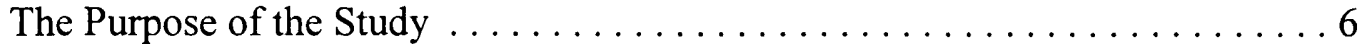

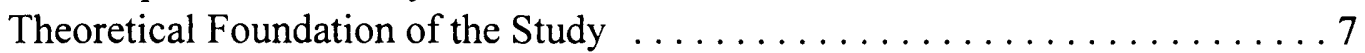

Basic Research Question and Related Questions ............... 8

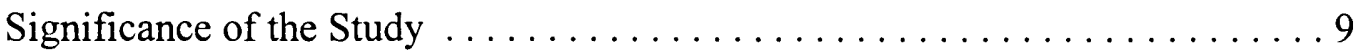

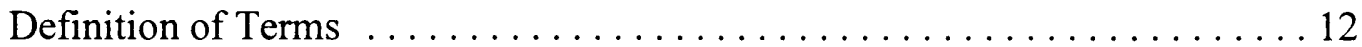

Assumptions ................................. 14

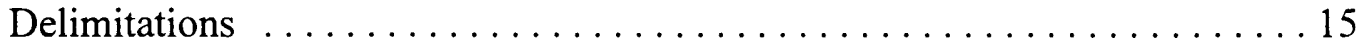

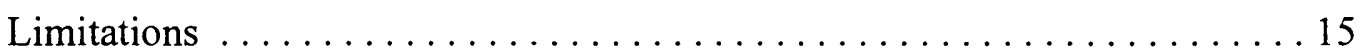

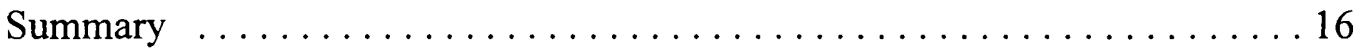

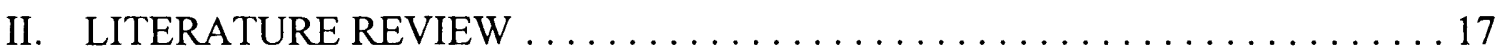

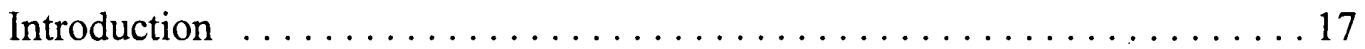

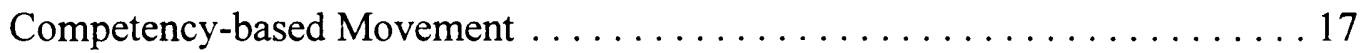

Competency-based Movement in Florida . . . . . . . . . . . . . 23

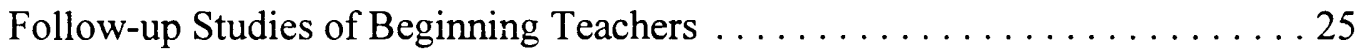

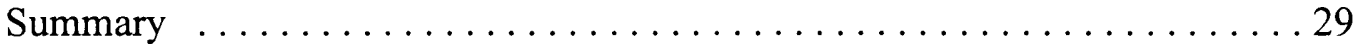

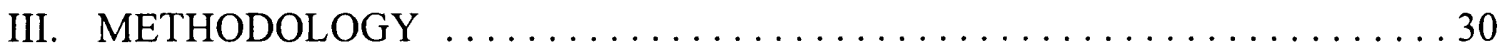

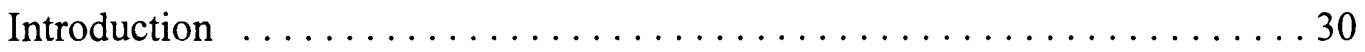

Population and Sample ............................. 30

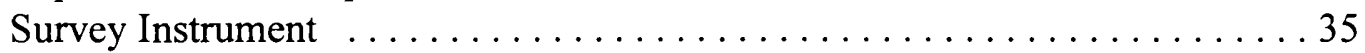

Data Collection .............................. 40

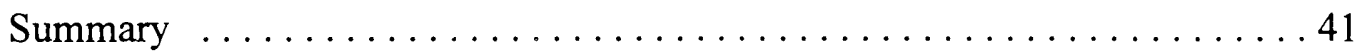

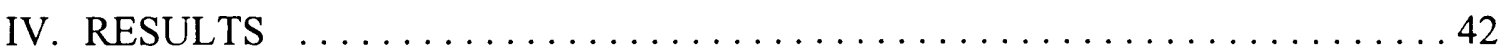

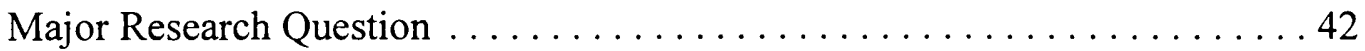

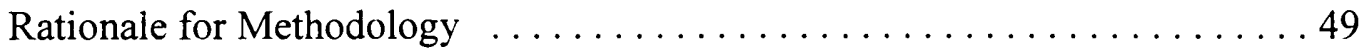

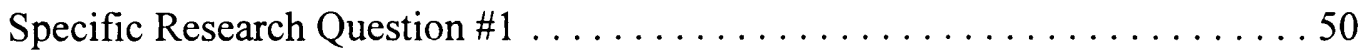

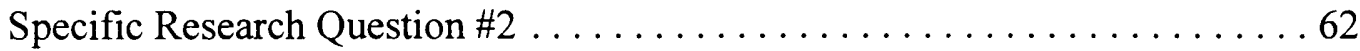

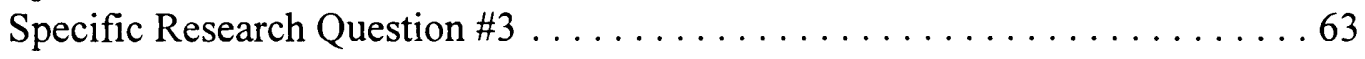

V. SUMMARY, DISCUSSION, CONCLUSIONS, AND RECOMMENDATIONS 71

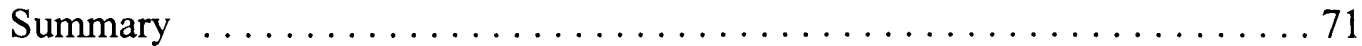

Discussion of Research Questions and Findings $\ldots \ldots \ldots \ldots \ldots \ldots 74$ 
PAGE

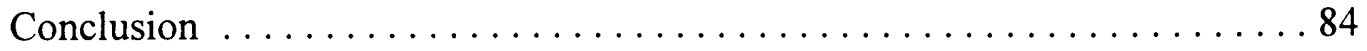

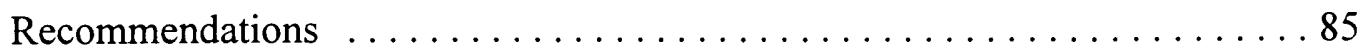

LIST OF REFERENCES REFERENCES . . . . . . . . . . . . . . . . . . . . 89

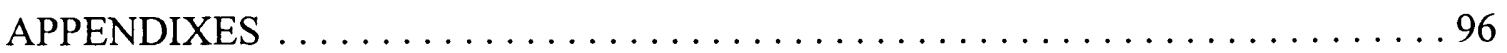




\section{LIST OF TABLES}

TABLE

PAGE

1 Type and Location of Graduating Institutions of Responding Teachers

2 Demographic Breakdown of Respondents by Gender and Ethnicity . . . . . . . . 34

3 Profile of School Level Where Beginning Teachers

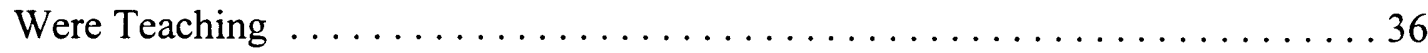

4 Means, Standard Deviation and Percentage of Preparedness for Each Competency in Descending Order . . . . . . . . . . . . . . . . . . . 44

5 Cumulative Frequency and Percent of Competencies That Each Person Felt Prepared to Implement . . . . . . . . . . . . . . . . . . . . 48

6 Means and Standard Deviations of Degree of Preparedness by Competency for Elementary Versus Middle and High School Teachers $\ldots \ldots \ldots \ldots \ldots . \ldots . \ldots 1$

$7 \quad F$ Values and Significance of $F$ for each of the 28 Competency Items Comparing Elementary Versus Middle and High School Beginning Teachers. ......... 56

8 Means and Standard Deviation of Degree of Preparedness by Competency for Elementary Versus Middle School Teachers . . . . . . . . . . . . . . . . 59

9 Means and Standard Deviation of Degree of Preparedness by Competency for Elementary Versus High School Teachers . . . . . . . . . . . . . . . 61

10 Univariate F-tests Comparing In-state Versus Out-of-state Graduating Institutions Including Means and Standard Deviation

11 Means and Standard Deviations for Competencies with Significant Differences for In-state and Out-of-state Graduating Institutions $\ldots \ldots \ldots \ldots \ldots \ldots$ 


\section{CHAPTER I}

Introduction

The purpose of this study is to investigate the perceptions of beginning teachers in Florida regarding their preparation as it relates to the Florida Essential Generic Competencies mandated by the state of Florida.

This section presents the background of the problem, the statement of the problem, the purpose of the study, the research questions, the significance of the study, the definition of terms, the assumptions, and the delimitations and limitations of the study.

\section{Background of the Problem}

Education plays an essential role in building strength from our society's growing ethnic and social diversity. Over the past 20 years, Florida has faced many challenges posed by the growth and changing demographics of its student population. According to the Florida Commission on Education Reform and Accountability (1994), these challenges include:

1. Increase in the number and percent of students who are disabled, whose native language is not English, and who are economically "disadvantaged."

2. Greater mobility of students within and among Florida districts, between Florida and other states, and between Florida and other countries. 
The Florida Commission also maintains that the state has successfully met these challenges. According to Blueprint 2000, a major legislative document for educational reform in Florida, despite these successes, the state and national economies and quality of life are at risk as the year 2000 nears (Florida Education Standards Commission, 1991). Blueprint 2000 is "one of the most comprehensive and dramatic reforms of a state system of public schools in our nation's history" (Florida Commission on Education Reform and Accountability, 1993, p. 2).

Florida is responding to the nation's growing concern about future economic success and societal changes by restructuring schooling for the next century. Florida is in the midst of a school improvement movement. If it continues as it is now envisioned and planned, there will be great changes in the state's schools, with teachers performing many new and demanding roles.

In 1993, the state legislature directed the Education Standards Commission (ESC) to identify the necessary competencies for teachers to implement the goals of the Education Accountability Act. The ESC divided its work into two phases: Phase I, identification of generic knowledge, skills, and dispositions needed by teachers and staff to implement Blueprint 2000, and Phase II, identification of critical events or benchmarks and levels of teachers' performance of the generic knowledge, skills, and dispositions for each benchmark.

The Commission has completed Phase I. Blueprint 2000 Goal 6 (the most relevant to the present study) identified 12 general principles and key indicators for each 
principle. Those principles have been called Accomplished Practices. They provide a framework for a model of professional growth for educators (Florida Commission on Education Reform and Accountability, 1994) (see Appendix A). The findings in this ESC report indicate that beginning teachers do not have the preparation time, depth or breadth of knowledge, or experience to acquire the high performance levels of skills, knowledge, and dispositions needed to effectively implement Blueprint 2000. The 12 generic principles and key indicators for each principle are reflective of higher standards in teacher education. The professional growth model is predicated upon three of the basic beliefs underlying Blueprint 2000: in continuous quality improvement, in higher standards, and the belief that all individuals can learn (Florida Education Standards Commission, 1994).

The belief in the integration of continuous growth of teachers toward accomplished practices as a model for preservice education, as well as for licensure, is a significant departure from the past (Sanders, 1994). As stated by the Florida Education Standards Commission, the Accomplished Practices establishes higher standards in areas such as assessment, planning, and creating learning environments, toward which future teachers will work from the time they enter preservice teacher education and throughout their professional life (Florida Education Standards Commission, 1994-95).

The ESC needed to review the present role of teachers and consider recommendations about the future preparation of the beginning teachers of the $21 \mathrm{st}$ century. The present study analyzes the perceived degree of preparation for each of 
Florida's current generic competencies also known as the Professional Skills (see Appendix B), as reflected in the results of a survey completed by beginning teachers throughout the state. Therefore, the results could contribute to the Commission's work by providing additional information in the area of teacher preparation.

The Accomplished Practices are more comprehensive than many of the Florida Essential Generic Competencies. Also, they are part of the professional model which is the basis for Blueprint 2000, an integral part of Florida's school improvement effort (Florida Commission on Reform and Accountability, 1994). In order to implement Blueprint 2000, teachers require specialized skills and knowledge. The Commission has already included in their report a combination of teacher competencies well established by other research groups such as the Interstate Teacher Assessment and Support Consortium (INTASC) and competencies that remain specifically distinctive to the needs of Florida public education (see Appendix A). The Commission believes that the current generic competencies have proven to be of great value to the education profession in the state since they were first adopted in 1981 (Florida Commission on Reform and Accountability, 1994). The generic competencies offered Florida educators a document founded on research and effective practice that could be used with confidence as a basis for teacher preparation, professional development, and assessment. Because the generic competencies clearly embody the essential skills of beginning teachers, they continue to be useful, though in a more limited way than in the past. 
In the 15 years since the identification of the generic competencies, there have been great and rapid changes in the classroom teachers' responsibilities. Today, more than ever before teachers are expected to teach students from varied cultural backgrounds, care for their physical and mental health, and work with parents as partners to best prepare their children to lead productive lives. Also, the technological advances of the last 25 years have created a global economy. Consequently, businesses face stiff competition from other countries around the world. For America to maintain its productivity and economic success, its citizens need new and higher-level skills (Blueprint 2000).

Multicultural awareness needs to be a part of all teacher's preparation if Florida is to meet the needs of its diverse student body. Similarly, instructional technology is an important component if Florida is to meet the technological advances faced by our society. Competencies must reflect societal needs. For example, "the teacher uses appropriate technology in teaching and learning processes" is listed as one of the Accomplished Practices in the Blueprint 2000 standards (see Appendix A). This Accomplished Practice enlarges one of the present generic competencies, addressing the use of computers in the classroom. The Education Standards Commission (1994) agrees that the search for fully comprehensive and authentic competencies is a continuous process, constantly affected by new knowledge as well as unprecedented responsibilities and the powerful effects of change. 
While the Florida Education Standards Commission continues to build a

restructured and reformed education system, the present study closely examines the preparation for the current Florida Essential Generic Competencies as they are perceived by beginning teachers across the state. The results of this study will, hopefully, provide additional justification for the Commission's recommendations and provide information to improve the state's teacher preparation programs.

\section{Purpose of the Study}

The purpose of the study is to investigate how Florida's beginning teachers perceive their preparation to demonstrate the Florida Essential Generic Competencies. The generic competencies were selected because they provide a set standard used by the state to measure the preparation of beginning teachers. They must be present in the curricula to receive state program approval. These competencies represent the basic skills needed by teachers to receive initial teacher certification.

This study represents the first single statewide survey conducted to collect information on the perception of beginning elementary, middle, and high school teachers as to their teacher preparation programs. The beginning teachers who graduated from private and public, in-state and out-of-state institutions, have indicated their perception of how well they were prepared to demonstrate the generic competencies after graduation. 


\section{Theoretical Framework of the Study}

There have been several frameworks proposed for examining conceptual variations in teacher education since the mid-1970s (Harnett \& Naish, 1980; Joyce, 1975; Kennedy, 1987; Kirk, 1986; Zeichner, 1983; Zimpher \& Harvey, 1987). There is considerable overlap in these theoretical perspectives, models and paradigms discussed by Feiman-Nemser. She identified five conceptual orientations in teacher preparation: (a) academic, (b) practical, (c) technological, (d) personal, and (e) critical/social. An orientation refers to a set of ideas about the goals of teacher preparation and the means for achieving them. Each orientation has a focus or thesis that highlights certain aspects of teaching, learning, and learning to teach; directs attention to a central goal of teacher preparation; and manifests itself in particular practices (Feimer-Nemser, 1990).

The technological orientation is one of five described. This one focuses on the knowledge and skills of teaching and the primary goal is to prepare teachers who can carry out the tasks of teaching with proficiency. Competence is defined in terms of performance (Feimer-Nemser, 1990). Research on teacher effectiveness done in the 1980s has presented a technology that can be taught to the future teachers. This instruction consists of generic teacher behaviors and strategies associated with student achievement. The discussion of the technological orientation needs to include competency-based teacher education and this is the focus of the present study.

This study centers on the notion that generic competencies are an integral part of the present teacher preparation program in the state of Florida. This author believes that 
the 27 essential generic competencies are a limited set of standards to be used for assessing the performance of beginning teachers. Even though teaching includes a great deal more than classroom instruction, the various activities of teaching (Green, 1971) may be thought of as a series of performances. Smith (1975) states that the same thing can be said of any professional practice that is professional--that is, that is based upon theoretical knowledge and insight--the training must be built upon and intimately connected to a suitable education. The key, then, to an adequate performance-based teacher training effort (as part of a program of teacher education) is an analysis of the activities of teaching. This study will analyze these activities of teaching (the generic competencies) from the perspective of the perceived degree of preparation of beginning teachers in Florida.

\section{Basic Research Question and Related Questions}

The basic research question of this study was: How do beginning teachers perceive their level of preparation regarding their demonstration of the Florida Essential Generic Competencies? This study identifies and categorizes the perceived degree of preparation for each of the competencies.

Also, the study seeks to answer the following three specific subsidiary questions:

1. Is there a significant difference in the perceived level of preparation between beginning teachers graduating from elementary, middle, and high school teacher education programs? 
2. Is there a significant difference in the perceived level of preparation between beginning teachers graduating from public and private colleges and/or universities?

3. Is there a significant difference in the perceived level of preparation between beginning teachers graduating from a college/university in Florida and an out-of-state institution?

The information to answer the above questions were provided by beginning teachers involved in the Professional Orientation Program (POP) during the 1992-93 school year. They voluntarily responded to the instrument, the POP survey used in this study (see Appendix C).

\section{Significance of the Study}

Properly trained teachers are a crucial component in any movement toward school improvement. However, even presently accepted best practices are not uniformly and thoroughly implemented in all Florida schools and classrooms. The apparent problem is that beginning teachers do not have the preparation, depth, breadth of knowledge, or experience to possess the high performance level of skills, knowledge, and dispositions necessary to be successful in the classroom. The Florida Education Standards Commission (1994) states that the teacher education programs in Florida need to prepare the future teachers to master the current 27 generic competencies as a minimum by the time they graduate. Additionally, teacher education units need to evaluate their teacher preparation programs on an ongoing basis. The accreditation and program approval 
processes are mechanisms for this evaluation. The two accrediting agencies are the Southern Association of Colleges and Schools (SACS), and for the public universities, the National Council for Accreditation of Teacher Education (NCATE). In Florida, teacher education colleges and schools must also meet standards required by the Department of Education (DOE), a state program approval agency and the Board of Regents (BOR), the agency responsible for degree approval.

All of the state program approval and accrediting organizations have specific standards addressing teacher competencies. For example, Standard 4 of the Department of Education states:

The curricular offerings in professional education provide sufficient opportunity to learn and practice appropriate theories, concepts, and strategies, as defined in the Florida Essential Generic Competencies. Courses and experiences show evidence of being well-planned and cohesive.

Members of the Department of Education teams are very careful to check for evidence as to where in the curriculum these competencies are presented in the teacher preparation program.

The document produced by the Florida Commission on Education Reform and Accountability, Blueprint 2000: A System of School Improvement and Accountability, provides guidance and direction for all elementary and secondary schools in the state, and also unifying goals in which postsecondary education can collaborate. It proposes seven statewide education goals and their associated standards. Standard 1 within Goal 6 is of 
special interest to this study because it addresses colleges of education and postsecondary institutions. The goal reads:

The schools, district, colleges of education, postsecondary institutions, and state ensure professional teachers and staff.

Goal 6 includes three standards.

Standard 1: All teachers and staff demonstrate the skills, values, and knowledge needed to assist students in meeting standards and outcomes in Blueprint 2000: A System of School Improvement and Accountability.

Standard 2: Each school provides a professional environment in which to work.

Standard 3: The state, district, and schools attract and retain an appropriate number of high-performing, professional teachers and staff, that reflects racial and ethnic diversity and includes persons with disabilities.

Currently, the state has not collected data to measure how well beginning teachers are prepared to demonstrate the Florida Essential Generic Competencies or how well they meet the objectives of Blueprint 2000. This study attempts to address this problem even though it is limited to the perceptions of the preparation of beginning teachers.

Limited information is available regarding teacher preparation from the results of the Professional Orientation Program (POP) for beginning teachers (see Definition of Terms). The 27 generic competencies examined in this study are part of the POP. Successful completion of POP at the end of the teacher's first year of teaching is required for State of Florida teacher licensing. If beginning teachers do not do well in the POP, 
the districts must supplement their education with inservice training. The school districts will have to remediate weaknesses that may have been caused by an inadequate teacher preparation program. It is important that the institutions preparing teachers do their best to contribute to the successful performance of their students in the POP.

Criteria for state approval of Florida teacher education programs require that at least $80 \%$ of the program graduates pass the Florida Teacher Certification Examination for the program to maintain approval by the Department of Education (Florida Statute $240.529,1979)$. Consequently, those preparing the curriculum for the preservice programs will be able to use the results of this study to make necessary modifications in the way competencies are presented in the courses.

This study is also significant because teacher education units in Florida are required to follow up with their graduates, collect and evaluate data to meet their own planning needs, as well as those required for accreditation. The findings from this study are expected to generate information that will assist institutions in the preparation for accreditation as well as improve their teacher education program.

\section{Definition of Terms}

BLUEPRINT 2000: A major legislative document for educational reform in Florida. The Florida Education Standards Commission has worked with Goal 6 (the most relevant to the present study) and has identified 12 generic principles and key indicators for each principle. Those principles have been called Accomplished Practices. They provide a 
framework for a model of professional growth for educators (Florida Commission on Education Reform and Accountability, 1994).

BEGINNING TEACHER: A teacher who is seeking a professional certificate (license) in Florida through a year-long supervised program (Osborne, 1988). In this study, this term is intended to represent the teachers who participated in the survey. These teachers represent a subset of those who successfully completed the Professional Orientation Program (POP).

COMPETENCY-BASED TEACHER EDUCATION (CBTE): A pre-service teacher education program in which competencies to be acquired and demonstrated by the student are stated in specific behavioral terms. Criteria to be applied in assessing the competencies are made explicit and the student is held accountable for meeting those criteria (Weber, Cooper, \& Houston, 1973). CBTE supports the rationale for the creation of the 27 Florida Essential Generic Competencies.

FLORIDA'S ESSENTIAL GENERIC COMPETENCY: It is "a conceptualization of a responsible and purposeful performance essential to the effective professional conduct of all teachers" (Capie, Anderson, Johnson, \& Ellet, 1979). As stated in the Florida Department of Education POP Policies and Procedures Manual, each applicant for initial professional certification needs to demonstrate on a comprehensive written examination or other procedure as specified by the state board, mastery of the minimum essential 
generic competencies (p. A-17). At the time of the study, there were 27 generic competencies which must be demonstrated for initial professional certification. The 28th competency was added and should be integrated into POP on or before July 1, 1995. Beginning teachers will have to identify and comprehend the codes and standards of professional ethics.

FLORIDA TEACHER CERTIFICATION EXAMINATION: A written examination, developed by the Florida Department of Education and is mandatory for initial teacher certification. This test consists of four subtests including, Reading, Writing, Mathematics, and Professional Education. This examination is a requirement which must be met by all beginning teachers.

PROFESSIONAL ORIENTATION PROGRAM (POP): A comprehensive program of support, training, and documentation of the generic competencies designed for a teacher applying for an initial regular Florida teaching certificate. POP is a three-year program, the first year being mandatory, for developing professional skills and competencies for beginning teachers. The participants of this study were completing this program when they responded to the survey.

\section{Assumptions}

This study makes the following basic assumptions: 
1. It is assumed the participants (beginning Florida teachers) will have sufficient understanding of the Florida Essential Generic Competencies to be able to rate each item of the survey instrument.

2. As in all studies based on a survey, the study assumes that the responses to items reflect valid responses regarding the teacher preparation program.

3. It is assumed that all participating county Professional Orientation Program Coordinators distributed all copies of the surveys sent to them.

4. All 27 Florida Essential Generic Competencies are considered to be of equal importance.

\section{Delimitations}

The following delimitation is acknowledged:

The findings of this study are limited to analysis of data collected through a written instrument completed by beginning teachers participating in the Professional Orientation Program in Florida. This instrument was returned to the POP Coordinators by February 1, 1993.

\section{$\underline{\text { Limitations }}$}

The following are three limitations to the study:

1. This is a post facto survey where the data have been collected by the Professional Orientation Program coordinators. There is no plan to follow up with nonrespondents or seek additional data. 
2. Generalization of the results is limited to the extent that the subjects represent a cross-section of beginning teachers in Florida. However, the conclusions to be reached in the analysis are applicable to the participants of the study. The conclusions and recommendations are intended to have general application to present and future teacher preparation programs.

3. The study is limited to the participants' perceptions and does not address their actual levels of performance in the 27 generic competencies.

\section{Summary}

Blueprint 2000, unlike earlier state initiatives, links seven goals to performance standards. While most of the goals have implications for colleges and universities, Goal 6 is the most applicable for teacher education programs. This goal states that teachers need to help students obtain high performance standards.

Even though this study does not address the actual level of performance of beginning teachers, it will identify their perceived degree of preparation for each of the Florida Generic Essential Competencies. This information may be used by teacher education units to improve their curriculum. Teacher preparation courses must be geared toward the development and acquisition of the generic competencies.

Chapter II will present a review of the literature related to national and state reform movements, the competency-based movement, and the results of similar studies dealing with the perceptions of beginning teachers regarding their teacher education preparation. 


\section{CHAPTER II}

\section{Literature Review}

\section{Introduction}

This study is intended to add to the knowledge of teacher preparation in Florida and the perceived acquisition of the 27 Florida Essential Generic Competencies. These competencies are considered necessary for teachers' success in the classroom. This review of the literature examines the development of the competency-based movement in the nation and in the state of Florida. The review concludes with selected research studies dealing with the perception of beginning teachers regarding strengths and weaknesses of their teacher preparation programs.

\section{Competency-based Movement}

The competency-based movement as it relates to teacher education attempts to improve the quality of American education by focusing on teacher training. There has been much argumentative discussion about the validity, appropriateness, and effectiveness of competency-based education. It is not the intent of this study to argue for or against it but to present information as to how this educational reform came about.

One of the earliest antecedents of the competency-based movement was the influence of business-like values in the early 1900s. Historically, the educational system has an excellent track record in adopting business management procedures to justify maintenance patterns (Callahan, 1962). "By 1907 there were indicators that aspects of 
the business ideology had been accepted and were being applied by educators themselves" (Callahan, 1962, p. 6). The impact of business in education resulted in an effort to make school curricula more practical and to extend vocational training.

In 1910, Frederick W. Taylor introduced a novel system for industrial management which came to be known as "scientific management." The system, which relied on measurements and standards, was designed to yield greater productivity from employees. "The publicity given scientific management and the great claims made in its behalf intensified the public's feeling that great waste existed everywhere, and at the same time offered a means of eliminating it" (Callahan, 1962, p. 46).

Shortly after the introduction of scientific management, the efficiency of American education came under attack. The pressure to apply scientific management to the school system became great, and educators responded. The application of this system proved difficult, since education had no "scientifically established standards." Consequently, the term "accountability," which some refer to as "the management ethic" (Johns \& Morphet, 1975, p. 40) was developed. The explication of this managerial ethic, which is tied to business and industry," is based on doing what we say we will do" (Johns \& Morphet, 1975, p. 40).

The antecedent of Competency Based Teacher Education (CBTE) lies in what Robert Boguslaw refers to as "the new nonsocial science administrative power elite" (Boguslaw, 1965). Perrow, an organizational theorist, refers to this era as the time when "the linear programmers, the budget experts, and the financial analysts, arrived with 
emergency systems theory concepts, with their P.P.B.S. and cost-benefit analyses" (Perrow, 1973).

The development of educational standards have followed closely those processes used in business, industry, and government operations (Johns \& Morphet, 1975). This may be illustrated by General McNamara's Program Planning Budgeting System (P.P.B.S.) being thought of as the answer to accountability in educational operations. This cost-effective, performance-based program of the armed services utilized instructional materials designed to teach servicemen to perform tasks adequately. The idea behind this system was that military training could achieve predetermined goals. For example, if personnel could be trained to use military equipment, why couldn't the educational system do the same.

Public criticism of education and the demand for accountability did not diminish over the years and the focus turned to teachers. In 1963, H. G. Rickover noted:

A fourth of our elementary school teachers have not attended college, half of our high school English teachers have not majored in English at college, you can be certified to teach in elementary schools in two-fifths of our states without meeting any requirements in English, and in this country as a whole, on the average, you can be certified to teach secondary school English on the strength of no more than two semester courses in beginning composition. (p. 208)

Rickover's observations called attention to the need to concentrate on teacher qualifications as a means to improve education. 
Atkin (1975) wrote that performance-based teacher education (PBTE) is the most visible manifestation at the university level of the accountability pressures on the educational system that came to full flower in the late 1960s. It became popular to describe schooling in terms of "inputs" and "outputs." The public were expecting changes in students and they were making demands as tax payers. Influential spokesmen for the teacher education enterprise responded by advocating PBTE programs. They believed that the future teachers needed to be trained in the necessary skills for them to be able to perform desired specified behaviors (Atkin, 1975). Teacher preparation revolved around competencies. The time to educate teachers to think of such topics as educational change, history of education, and moral implication of teaching suffered at the expense of time spent to teach specified skills (Atkin, 1975). The PBTE movement was supported by the American Association of Colleges for Teacher Education (AACTE), and by the state teacher certification authorities in most states.

Colleges of education faculty did not pay much attention to the PBTE and the CBTE until the AACTE and other influential funding agencies supported them (Broudy, 1973). When certification boards and state departments of instruction threatened to withhold certification from programs that were not competence or performance based, schools got into the act.

The final thrust for the competency-based movement, was propelled by the United States Office of Education (USOE) Elementary Models Project. "Each of the ten models relatively independently arrived at an emphasis on competencies. By early 1972 some 17 
states either had announced certification changes to be based on competencies or had declared their interest or intentions" (Houston \& Howsam, 1972, p. ix).

Joyce and Harootunian (1967) described teaching in terms of behavior, but pointed out that the effective teacher is one that selects from among a wide range of behaviors those most appropriate for a given situation.

Truesdell (1978) writes that teaching theory should be derived from theories of learning, yet must be based on knowledge and behavior that goes beyond that implied by learning theory. Teaching may be described in terms of behavior exhibited by the teacher as he or she affects student learning. Teaching behavior has several phases or steps that include planning, diagnosing, instructing, and evaluating. Although teaching behaviors may be described as discrete acts, they are interdependent and will vary as variables within the teaching situation change. Effective teaching is rational and results from a decision-making process that the teacher implements as he or she proceeds through the phases of teaching.

Johns and Morphet (1975) defined competency-based education as a technique for teacher education based on systems management design: “. . . in which goals are clearly specified and agreed upon in advance of instruction. The student-teacher must be able to demonstrate his or her ability to promote desirable learning or exhibit behaviors known to promote it and is held accountable for attaining a given level of competency in performing the essential tasks of teaching" (p. 44). 
Bowers states that the "use of such terms as input, output, system, component, interface, functional, output administration, process, and feedback, are forcing discussions of social processes and individual experience into a highly objectified mode. Discussions about inner experiences are tactfully put down as dealing with a non-reality because it is neither observable nor measurable. Such are categorized as ritualistic communication. The fate of such areas as ethics and metaphysics under CBE translations are being put into the special category reserved for the 'impractical"' (Bowers, 1977).

Feiman-Nemser (1990) writes that competency-based teacher education requires that teacher educators explicitly state the competencies students will acquire in their program and the criteria by which they will be assessed. Typically, a competency-based program consists of instructional modules, sets of learning activities designed to help students achieve specific objectives (Elam, 1971; Houston, 1974; Houston \& Howsam, 1972). Students' rates of progress through the programs are determined by demonstrated competence rather than course completion.

In summary, the competency-based movement was a response to years of external pressure. The movement offers practical/vocational training, such as was campaigned for in the early 1900s. It sets standards and makes students accountable for the acquisition of criterion behaviors. It concentrates on teacher qualifications as a means to improve the efficiency and effectiveness of education. The competency-based movement was spurred on by the demand for accountability, and is driven by the desire for quality. 


\section{Competency-based Movement in Florida}

The Florida Legislature required students in the teacher education programs in Florida in 1978 and 1979 to complete a year-long internship prior to issuance of the initial regular teaching certificate. This legislation represented a major step in the improvement of the teacher training and certification process. One of the basic provisions of the 1978 Committee Substitute for Senate Bill 549 (CSSB 549) was:

A delineation of certain identified competencies believed to be essential to effective teaching. Additionally, CSSB 549 required that beginning July 1, 1981, certification would be granted, upon application, to those persons meeting the prescribed requirements. According to section 231.17, Florida Statutes, these requirements included:

Demonstration on a comprehensive written examination and through such other procedures as may be specified by the state board of mastery of those minimum essential generic and specialization competencies and other criteria as shall be adopted into rules by the state board.

Universities throughout the state have revised their teacher preparation program to help their graduates to meet the Florida Essential Generic Competencies.

Districts and non-public schools needed a valid and reliable instrument for assessing the successful demonstration of the essential teaching competencies. For this purpose, a performance measurement system, based upon research and best practice was developed. A coalition of 64 school districts, the state universities, private colleges, and 
several private schools joined in an effort to develop a system to measure beginning teacher performance in the Fall of 1981. The result was the identification of at least 121 specific teacher behaviors that had been shown through research to be directly related to increased student achievement and improved classroom conduct. This work resulted in the Florida Performance Measurement System (FPMS). It is organized into six domains: (a) instructional planning, (b) management of student conduct, (c) instructional organization, (d) presentation of subject matter, (e) communication, and (f) testing. Each domain consists of specific behaviors grouped into sets of competencies. Overall, the six domains include 128 behaviors organized into 27 competency categories. These competencies became the competency-based model for teacher education in Florida. They were adopted in Florida Statutes and State Board of Education Rules.

The development and implementation of the original generic competencies for teacher certification was enacted into a law as a committee substitute for Senate Bill 549 (CSSB 549), and became Section 231.17 of the Florida Statutes. Since the original work and recommendations of the coalition, there have been additional competencies included in State Board of Education Rules for approval of Teacher Education Programs. Such legislative changes are disseminated by the Florida Department of Education to all institutions graduating teachers on a regular basis.

The mechanism employed by the state to make certain that the graduating teachers had mastered the generic competencies was the implementation of the Beginning Teacher Program (BTP). The BTP was developed to assess and train new teachers with an 
appropriate set of professional skills. The BTP (a) increases student learning by providing a set of supervised support services for teachers in the first year(s) of teaching in Florida to assist them in their continuing professional development, and (b) meet the requirements of Section 231.17(3) Florida Statutes and Rule 6A-5.75, Florida Administrative Code (Turlington, 1982).

Even though the name of the BTP changed to Professional Orientation Program (POP), the ultimate goal is still the same. That goal of the POP is to develop professional growth that will support research-based preservice training through systematic application of a common knowledge base to refinement of training, performance measurement, feedback to departments and, colleges of education.

\section{Follow-up Studies of Beginning Teachers}

This final part of the review of the literature presents the results of similar studies dealing with the perception of beginning teachers regarding their teacher education preparation.

Oguntade (1983) assessed the utility and adequacy of the content of professional teacher education experiences offered by state approved teacher education programs in Florida. She specifically investigated the essential generic competencies which are the skills and knowledge which must be demonstrated and evaluated in the Beginning Teacher Program, now the Professional Orientation Program. 
The Oguntade (1983) study consisted of 60 beginning teachers representing 15 districts and she cautioned against broad generalizations due to the small sample and incomplete participation of all districts in Florida. Oguntade (1983) recommended a similar study of this kind be conducted statewide after the beginning teacher program had been in existence for a few more years. The findings from this study indicated that beginning teachers in Florida perceived their preparation as adequate in most of the teaching competencies. The areas of greatest strength in preparation were related to communication skills and teaching methods. Communication skills such as: sequencing objectives, listening and reading comprehension, written and oral communication received the highest rating of adequate preparation. (The items in the POP survey used in the present study matching those areas are 14 and 16. See Appendix C). However, there were seven competency areas in which beginning teachers perceived that preparation in their teacher education programs as inadequate. The seven competency areas in which beginning teachers perceived themselves as being inadequately prepared for dealt with the area of routine operation and classroom management; human growth and development in relation to the academic counseling of students relative to their social development; instructional needs of handicapped children; and instructional skills which assist students' positive peer interaction and value clarification. (The items in the POP survey matching these areas are $1,2,3,8,9,17$, and 19. See Appendix C). 
Twelve years have gone by since Oguntade's (1983) study. The present study compares present perceptions of beginning teachers with her results as they relate to the perceived adequacy of the teacher preparation programs throughout the state of Florida.

Drummond (1991) conducted a study to determine how beginning teachers evaluated preservice teacher education and performance. His survey only included graduates from the University of North Florida from 1988 to 1990 who had been hired to teach in Florida. The participants rated themselves on their performance of the 27 generic competencies. Results indicated that skills such as classroom management and organization were reported both as areas of strength and weakness. They felt well prepared to demonstrate interpersonal skills as opposed to their conferencing skills in which they felt unprepared.

The survey was similar to the one used in the present study. The beginning teachers were asked to rate their performance in the first year of teaching on the 27 generic competencies using a five point scale, 1 being low and 5 being high. Approximately 400 surveys were mailed and 90 returned (23\%). The list of beginning teachers participating in the study was provided by the Florida Department of Education and it contained the names of beginning teachers over a three-year span. There were significant differences between the groups of beginning teachers' ratings on two competencies. The competency that deals with conducting and sequencing related shortrange objectives for a given subject area, was found to be significant at the .04 level. The 1989 beginning teachers rated this competency higher than the 1988 teachers. The 
competency dealing with the use of the computer in education was significant at the .02 level. The 1988 and 1990 beginning teachers rated this competency higher than the 1989 teachers (Drummond, 1991).

Other findings of the study suggest that the highest rated competency was the one that deals with arranging and managing the physical environment to facilitate instruction and ensure student safety. The second highest was communicating effectively using verbal and nonverbal skills. The third was enhancing students' feelings of dignity and self-worth and the worth of other people. The fourth was formulating a standard for student behavior in the classroom. The fifth was relating to students' verbal communication in ways that encourages participation and maintains academic focus.

The five lowest rated competencies were: uses the computer in education, recognizes signs of alcohol and drug abuse in students, identifies long-range goals for a given subject area, determines the entry-level knowledge of students for a given set of instructional objectives, and recognizes the overt physical and behavioral indicators of child abuse.

Drummond's (1991) survey also included written critique about the teacher preparation programs. Both the ratings of the competencies and responses provided valuable information which led to recommendations to improve teacher preparation programs. The recommendations included developing an assessment center to work with both preservice and inservice teachers. This center could help identify gaps in the students' preparation before they went out for their final internship. Also recommended 
was the need for faculty of the methods and core courses to plan together as a team in order to share new and innovative trends and practices.

\section{$\underline{\text { Summary }}$}

This review of literature provides the history of the competency-based educational movement from the influence of the "scientific management" system introduced by Frederick W. Taylor in 1910 to its present implementation in the state of Florida. There are also some critical perspectives presented from different theorists like Raymond Callahan, H. G. Rickover, Roe Johns, and Morphet.

This chapter ends with the results of data generated by Oguntade (1983), and Drummond (1991), providing additional information to the area of competency-based programs. The findings and recommendations from these studies present strengths and weaknesses of the competency-based approach. 


\section{CHAPTER III}

\section{Methodology}

\section{Introduction}

This section describes the population and sample of beginning teachers in Florida public and private schools surveyed in this study, the survey instrument and data collection procedures. The purpose of this study is to investigate how beginning teachers perceive the adequacy of the preparation provided by their teacher education program. This study follows the descriptive method of research. According to Gay (1992), "Typical descriptive studies are concerned with the assessment of attitudes, opinions, demographic information, conditions, and procedures" ( p. 218). The study analyzes selfreported survey data collected in January, 1993 from graduates of Florida's teacher education certification program.

\section{Population and Sample}

The population of this study was beginning teachers who participated in the Professional Orientation Program (POP) in 68 counties (see Appendix D) throughout the state of Florida during the 1992-93 academic year. This program is required for all beginning teachers in the state. According to the Florida Department of Education Professional Orientation Program Current Status Report, 5,076 beginning teachers successfully completed the program that year (see Appendix E). This group of beginning teachers were sent the POP survey by their district POP Coordinator. A total of 1,995 
teachers completed and returned the survey. This group represents $39 \%$ of the beginning teachers who graduated from private and public institutions, in-state and out-of-state (see Appendix F). They constitute a convenience sample of the beginning teachers completing teacher education programs in Florida.

An attempt was made by this researcher to determine if these data are representative of the total population of participants of the Professional Orientation Program during the 1992-93 school year. Members of the State of Florida Department of Education were very supportive of this research. They provided total number of participants by gender and ethnicity for completers and non-completers of the POP. The total number of respondents by graduating institution and program were not available. Consequently, to evaluate whether the sample was representative of the population from which it was drawn, chi-square goodness-of-fit tests were used to examine the similarity of the proportion of subjects in the sample and the population on variables of gender and ethnicity. The reason for performing these tests addresses the generalizability of the results of the study.

Separate tests were performed to determine if the proportion of respondents were similar in gender and ethnicity to those of the population. The null hypotheses being tested was that the proportion of subjects in the sample was not significantly different from that of the population based on gender or ethnicity. The first test compared the percentage of males and females in the sample to the total population of participants. It resulted in a chi square value of 16.30 with 1 degree of freedom and a significance of 
$\mathrm{p}<.0005$. There was a significantly higher percentage of females in the sample than the number of female respondents in the total population of beginning teachers. The second test was performed to examine the ethnic composition of the sample. It resulted in a chi square value of 6226.80 with four degrees of freedom and a significance of $p<.0005$. The number of African American and Latino respondents were higher in the sample than in the total population. In both tests the null hypotheses was rejected. The conclusion from these results is that the sample was not representative of the general population of beginning teachers for gender and ethnicity.

There are 29 Florida teacher preparation institutions represented in the study. There were $531(27 \%)$ respondents who attended out-of-state teacher education programs. Eleven $(0.6 \%)$ of the respondents in the survey did not identify their graduating institution. Therefore, they were not included in the study. Table 1 shows the number and percentage of participating beginning teachers by the type of institution they graduated from (in-state, out-of-state, private, and public). Out of a total of 1,995 beginning teachers responding to this part of the survey, $319(16.9 \%)$ graduated from private, in-state institutions and 1,104 (56.1\%) graduated from public, in-state institutions.

Not all respondents answered all questions. Consequently, there are missing values in all the tables presented in this study causing the totals not to reflect the responses of the 1,995 teachers who completed and returned the instrument. The number 
Table 1

Type and Location of Graduating Institutions of Responding Teachers

Type and Location

Frequency

$\%$

In-State

Private

319

16.9

Public

1104

56.1

Out-of-State

531

27.0

Total Responding

1954

100.0

Note. Non-respondents $=41$.

of those beginning teachers not responding to a particular question is noted at the bottom of each table.

As previously stated, the beginning teachers participating in this study passed the Florida Teachers' Exam, taken after graduation, and were issued a temporary certificate by the Teacher Certification Office in the Florida Department of Education. These graduates were actively seeking to complete the necessary requirements to obtain a fulltime teaching certificate through participation in a year-long, supervised internship (Professional Orientation Program).

As shown in Table 2, the demographic characteristics of the 1,995 beginning teachers who participated in this study include gender and ethnicity. The majority of the respondents were female $1,576(83 \%)$. Based upon the specific ethnic categories used in the POP survey, Anglos represented the largest groups of respondents 1,342 (71.2\%). 
Table 2

Demographic Breakdown of Respondents by Gender and Ethnicity

\begin{tabular}{lrrrrrrr}
\hline \multirow{2}{*}{ Ethnicity } & \multicolumn{2}{c}{ Female } & \multicolumn{2}{c}{ Gender } & \multicolumn{2}{c}{ Male } & \multicolumn{2}{c}{ Total } \\
& \multicolumn{1}{c}{$\mathrm{n}^{2}$} & $\%$ & $\underline{\mathrm{n}}$ & $\%$ & & $\underline{\mathrm{n}}$ & $\%$ \\
\hline African American & 107 & 5.67 & 34 & 1.80 & 141 & 7.5 \\
Anglo & 1139 & 60.42 & 203 & 10.77 & 1342 & 71.2 \\
Asian & 10 & .53 & 3 & .15 & 13 & .7 \\
Latino & 95 & 5.03 & 27 & 1.43 & 122 & 6.5 \\
Native American & 121 & 6.42 & 22 & 1.16 & 143 & 7.6 \\
Other & 104 & 5.52 & 20 & 1.06 & 124 & 6.6 \\
Total & 1576 & 83.6 & 309 & 16.40 & 1885 & 100.0 \\
\hline
\end{tabular}

Note. Non-respondents $=110$.

The balance of the sample consisted of Native American 143 (7.6\%), African American 141 (7.5\%), "Other" 124 (6.6\%), and Latino respondents 122 (6.5\%).

Hahn (1992) believes that the assessment of demographic identity in a society with a culturally diverse and rapidly changing population is extremely difficult. Hahn examined and challenged four assumptions associated with racial/ethnic demographic research. First, he stated that there is an assumption that categories of race and ethnicity are consistently defined when, in fact, terminology and categorization differ from source to source and region to region. Second, Hahn also questioned the assumption that the racial and ethnic categories used by researchers are adequately understood by those being surveyed, e.g., do respondents indicate the correct racial/ethnic group from which they 
belong? This may have been an assumption on the part of those who designed the POP survey instrument. It is possible that the categories were not clear to the respondents.

The Latino representation in Table 2 may not really reflect the correct count and percentage of respondents for this particular group. Latino may not be the choice of Hispanics or those of a similar ethnic background. Since those individuals would not consider Latino an ethnicity category, they may have selected the "Other" category. The same may be true for the Native American. This may be the reason why the results of the chi-square goodness-of-fit tests suggested that the sample of this study was not completely representative of the general population of beginning teachers for ethnicity. Hahn's third assumption states that the response rates are similar for all racial and ethnic populations. Finally, Hahn questioned the assumption that individual responses to questions of racial and ethnic identity are consistent in different surveys and at different times.

One of the variables analyzed in this study is the school level where the beginning teachers were working at the time they participated in the POP survey. Table 3 shows the number and percentage of participants teaching at the elementary, middle and high school levels.

\section{Survey Instrument}

The instrument, referred to as the Professional Orientation Program (POP) survey (see Appendix C), was developed in collaboration with the members of Department of 
Table 3

Profile of School Level Where Beginning Teachers Were Teaching

\begin{tabular}{lll}
\hline & & $\%$ of Those \\
School Level & Frequency & Responding
\end{tabular}

Elementary

Middle School

High School

Total
1117

417

289

1823
61.3

22.9

5.8

100.0

Note. Non-respondents $=172$.

members of the Florida Association of Colleges of Teacher Education, and the Education (Bureau of Teacher Education and Education Standards Commission), the Professional Orientation Program (POP) State Coordinator. The Project Director of Program Review in the College of Education at the University of South Florida coordinated the development and administration of the survey.

The survey measures the perceptions of beginning teachers in several areas including preparation at graduation and initial demonstration success as it relates to the Florida Essential Generic Competencies; general perspective on their teacher education program and perspectives on the profession.

Prior to this survey, the teacher education units throughout the state were required to develop and administer their own instruments in order to gather evaluative data to meet 
their own needs, as well as the requirements for State Program Approval, NCATE accreditation, and SACS accreditation. The POP survey is the first survey of its kind that represents a statewide effort to centralize baseline data, allowing the comparison of graduates from the different teacher education programs in Florida. For this reason there was wide support for the use of this survey throughout the state.

The costs of development, duplication and distribution of the survey were all provided by the Project Director of Teacher Preparation in the College of Education at the University of South Florida. The Professional Orientation Program Coordinators for each of the 68 counties in Florida were responsible for the POP survey distribution in their respective counties. Each coordinator received enough copies of the survey, with a cover letter, for distribution to each of the participants of the POP in their county. The survey was returned to the POP Coordinators by February 1, 1993.

The survey was divided into four sections. The first section (29 items) sought demographic information, e.g., gender, ethnicity, graduating institution, highest degree completed, area of certification, type of present teaching position, and place of employment.

The second section (28 items) titled "Competencies" addresses the 27 Florida Essential Generic Competencies in terms of both perceived preparation and success in implementation. These competencies have indicators which further describe the observable behavior of the teacher (Appendix B). Competency 2 reads: Enhances students' feelings of dignity and self-worth and the worth of other people including those 
from other ethnic, cultural, linguistic, and economic groups. In the POP survey, this competency was split into two items $(2,3)$. Item 2 reads: Assist students in developing positive self-concepts, values, attitudes and beliefs. Item 3 reads: Assist students in appreciating and respecting persons from various ethnic, cultural, linguistic, and economic groups. For competency 16 , the POP survey also used two items $(17,18)$. Competency 16 reads: Creates and maintains academic focus by using verbal, nonverbal, and/or visual motivational devices. Item 17 reads: Modify instructional strategies during learning activities based on student responses and needs. Item 18 reads: Use student ideas, talents, and products to secure interest and maintain attention. Competencies 24 and 25 were combined into one item for the POP survey (26). Competency 24 reads: Constructs and assembles classroom tests and tasks to measure student achievement of objectives. Competency 25 reads: Establishes a testing environment in which students can validly demonstrate their knowledge and skills and receive adequate information about the quality of their test performance. The survey item (26) which combines the two (24 and 25) competencies reads: Select/develop/ modify and use a variety of assessment strategies, including classroom tests, to evaluate student progress and achievement. The reason for these variations is due to the way the generic competencies are written. The two that were divided include more than one skill. The two that were combined are very similar competencies. To avoid confusion, the numbers used throughout this study represent the survey items and not the actual Florida Essential Generic Competencies numbers. 
This study was limited to the analysis of perceived preparation of beginning teachers. Participants were asked to rate each competency by indicating their degree of professional preparation, using the following numerical scale: Not prepared at all (1), only minimally prepared (2), moderately well prepared (3), very well prepared (4), and not applicable (NA). The NA responses were not included in the analyses of data for this study.

The third section (26 items) titled "Perspectives on the Program" included statements characteristic of the teacher education program they completed. The fourth section (25 items), titled "Perspectives on the Profession," included questions related to future plans in their profession, support during their beginning teaching experience, and satisfaction with different aspects of teaching. The fifth and last section titled "Comments" solicits overall comments from the beginning teachers regarding strengths of their teacher education program and suggestions for improving it.

This study concentrates on the data generated by sections one and two which list the demographic data and generic competencies respectively. Within the latter section, the subjects rated each of the Florida Essential Generic Competencies according to their perceived degree of professional preparation. The demographic information in Section I represents the independent variables for which the dependent variables in the study (Section II) are compared. In order to narrow the scope of this study, data from Sections III, IV, and V, were not utilized. These data could be the basis for future research studies. 
Reliability of the instrument estimates "internal consistency by determining how all items on a test relate to all other items and to the total test" (Gay, 1992, p. 166). Since the items within Section II of the survey are scored such that different answers are worth different numbers of points, (e.g., 1, 2, 3, or 4), then Cronbach's Alpha (a), also referred to as Cronbach Coefficient Alpha, can be used. This statistical process was conducted to determine the reliability of the 28 items listed in the survey for Section II. The reliability coefficient for the 28 items was Alpha $=.96$.

\section{Data Collection}

All districts were asked to mail the surveys to participants. The instructions to all those who participated were the same. The POP coordinator for each district was responsible for the distribution of the surveys. The directions to complete the survey were written on the survey's cover letter (see Appendix C). The letter also included a statement that all data collected would be used only for analysis of this study and would be kept in strictest confidence. The approximate time to complete the survey was 45 minutes. Participants returned the surveys to their district POP Coordinators, in the selfaddressed stamped envelope provided, who sent them to the Evaluation and Testing Office of the University of South Florida for computer scanning. This researcher is not aware of any follow-up procedures to improve the response rate. 
The completed surveys were returned to the University of South Florida and were entered into a computer file suitable for data analysis. A copy of the original file was sent to this researcher for use in this study.

\section{Summary}

This study analyzes the impact that the teacher preparation programs have on beginning teachers in Florida as to the degree in which they perceive their level of preparation regarding their demonstration of the Florida Essential Generic Competencies. This information was obtained based on the perception of the 1992-93 beginning teachers. The majority of the respondents were female (83\%). Anglos represented the largest group of respondents 1,342 (71.2\%) with Native American 143 (7.6\%), African American 141 (7.5\%), Other 124 (6.6\%), and Latino respondents 122 (6.5\%) making up the rest of the sample. The respondents were teaching at elementary schools 1,117 (61.3\%), middle schools 417 (22.9\%), and high school $289(15.8 \%)$ levels when they participated in the survey. The survey instrument has a high level of reliability (Alpha

96). A detailed description of the results of the data collected through the administration of this instrument will be presented in Chapter IV. 


\section{CHAPTER IV}

\section{Results}

This chapter provides a summary of the results. The study examines the perception of preparation of the beginning teachers in terms of the several variables previously indicated. It includes a discussion of statistical methods used to answer the research and related questions.

\section{Major Research Question}

In order to answer the major research question of this study: How well do beginning teachers perceive their degree of preparation to demonstrate the generic competencies, several methods were used. The survey data were ranked in order to present means, standard deviations, and frequency distributions for each of the items representing the generic competencies.

The responses were examined to determine to what degree beginning teachers felt prepared on the various competencies. To accomplish this, the original data were recoded from its 4-point scale of 1 (not prepared at all); 2 (only minimally prepared), 3 (moderately well prepared), and 4 (very well prepared) to a binary scale of 1 (not prepared) or 2 (prepared). The actual recoding involved combining responses of 1 or 2 into a 1 (not prepared) and responses 3 or 4 into a 2 (prepared). The binary scale facilitates the clustering of generic competency items into five categories by percentage 
of preparation (Category I - 90\% or greater, Category II - 80-89\%, Category III - 70-79\%, Category IV - 60-69\%, and Category V - 50-59\%).

A frequency distribution based on the participants' recoded responses determined what percentage of the beginning teachers considered themselves prepared or not prepared to demonstrate each of the competency items. Table 4 shows the percentage of preparation calculated for each competency examined. It also includes the means and standard deviations for each competency based upon the original scaled responses and not the recoded responses described above. Then, based on the recoded responses, they are presented in descending order by the percentage of preparation calculated for each.

The competency items were further grouped into five categories representing $10 \%$ intervals. Even though other intervals could have been used to cluster the competencies by categories, the $10 \%$ intervals seemed appropriate for the purpose of looking at the data. This division allowed for the top and bottom categories to have fewer competencies and, consequently, emphasize their importance. Category I includes competency items for which at least $90 \%$ of the respondents felt prepared to demonstrate. As Table 4 indicates, teachers felt most prepared in constructing and sequencing short-range objectives, communicating effectively, and using feedback to help students during instruction and after assessment. 
Table 4

Means, Standard Deviation and Percentage of Preparedness for Each Competency in Descending Order

$\begin{array}{llll}\text { Competency Item } & \text { Mean } & \text { SD } & \% \text { Prepared }\end{array}$

CATEGORY I $90 \%$ or Greater Preparedness

12. Construct and sequence short-range objectives

for a given subject area

.72

90.9

16. Communicate effectively using verbal and non-verbal skills to enhance student performance

90.4

24. Use clear feedback (both praise and correction) to inform and help students during instruction and after assessment

\section{CATEGORY II $\quad 80 \%$ - 89\% Preparedness}

20. Provide directions appropriate to instructional activities, and ensure comprehension of those directions

14. Select/develop and sequence learning activities appropriate to instructional objectives and student learning needs

22. Provide appropriate and varied practice activities, and monitor performance on these activities to promote learning and retention

25. Conduct systematic reviews of subject matter before, during, and after lessons

23. Show acceptance and value of student responses, and redirect digressions without devaluing student responses

21. Use both low and high order questioning techniques to stimulate thinking and check comprehension

26. Select/develop/modify and use a variety of assessment strategies, including classroom tests, to evaluate student progress and achievement 
13. Use a variety of materials and media based upon curricular objectives, student needs, and available resources

1. Match instructional strategies to student learner needs

2. Assist students in developing positive self-

17. Modify instructional strategies during learning activities based on student responses and needs

8. Implement school rules and maintain a standard of classroom conduct

18. Use student ideas, talents, and products to secure interest and maintain attention

19. Teach various forms of knowledge, such as concepts, laws, law-like principles, academic rules and values

9. Use verbal/non-verbal techniques, parents, and school/community resources to reinforce or modify student behaviors

\section{CATEGORY III $\quad 70 \%$ - 79\% Preparedness}

4. Arrange classroom furniture, equipment, and instructional aids to facilitate teaching, learning, and safety

27. Record and report individual and class progress in accordance with pertinent laws and policies 


\section{CATEGORY III (CONTINUED)}

11. Formulate long-range goals that are both consistent with state and district goals and appropriate to student needs

.88

73.0

3. Assist students in appreciating and respecting persons from various ethnic, cultural, linguistic, and economic groups

CATEGORY IV $\quad 60 \%-69 \%$ Preparedness

10. Determine students' entry level knowledge/ skills using diagnostic tests, teacher observation, and student records

CATEGORY V 50\% - 59\% Preparedness

28. Integrate computers in instruction

7. Manage situations involving child abuse and/or neglect

5. Manage situations involving severe emotional stress

6. Manage situations involving alcohol and drug abuse

Category II includes those competency items for which at least $80 \%$ felt prepared to demonstrate. As Table 4 indicates, this category includes a wide range of skills. The top highest quartile $(25 \%)$ of ranked competencies were providing directions, selecting/developing and sequencing planning activities, providing appropriate activities, and conducting systematic reviews of subject matter. 
Category III includes four competency items for which at least $70 \%$ felt prepared to demonstrate. This category includes arranging classroom furniture, recording and reporting individual class progress, formulating long-range goals, and assisting students in appreciating and respecting various groups.

Category IV includes one competency item for which at least $60 \%$ felt prepared to demonstrate. The item deals with determining students' entry level knowledge/skills using diagnostic tests, teacher observation, and student records.

Category V includes four competency items for which at least $50 \%$ felt prepared to demonstrate. This category includes managing situations involving severe emotional stress, child abuse and/or neglect, alcohol and drug abuse, and integrating computers in instruction.

Another analysis conducted further illustrates the scope of perceived preparation by showing the number of competency items the respondents felt prepared to demonstrate in their classrooms. The results varied from ten beginning teachers who felt unprepared to demonstrate any of the competency items to 304 beginning teachers who felt prepared to demonstrate all 28 competency items representing the generic competencies. As shown in Table 5, approximately 50\% of the respondents felt prepared to demonstrate 24 or more of the 28 competency items. 
Table 5

Cumulative Frequency and Percent of Competencies That Each Person Felt Prepared to Implement

\begin{tabular}{|c|c|c|c|c|}
\hline & $\begin{array}{c}\text { \# of Competencies } \\
\text { Respondents } \\
\text { Felt Prepared }\end{array}$ & $\begin{array}{c}\text { \# of } \\
\text { Respondents }\end{array}$ & $\begin{array}{l}\text { Cumulative } \\
\text { Frequency }\end{array}$ & $\begin{array}{c}\text { Cumulative } \\
\%\end{array}$ \\
\hline & 0 & 10 & 10 & .7 \\
\hline & 1 & 9 & 19 & 1.4 \\
\hline & 2 & 11 & 30 & 2.2 \\
\hline & 3 & 2 & 32 & 2.4 \\
\hline & 4 & 5 & 37 & 2.7 \\
\hline & 5 & 7 & 44 & 3.2 \\
\hline & 6 & 7 & 51 & 3.7 \\
\hline & 7 & 6 & 57 & 4.2 \\
\hline & 8 & 7 & 64 & 4.7 \\
\hline & 9 & 6 & 70 & 5.1 \\
\hline & 10 & 16 & 86 & 6.3 \\
\hline & 11 & 11 & 97 & 7.1 \\
\hline & 12 & 20 & 117 & 8.6 \\
\hline & 13 & 16 & 133 & 9.8 \\
\hline & 14 & 28 & 161 & 11.8 \\
\hline & 15 & 21 & 182 & 13.4 \\
\hline & 16 & 27 & 209 & 15.4 \\
\hline & 17 & 33 & 242 & 17.8 \\
\hline & 18 & 44 & 286 & 21.0 \\
\hline & 19 & 40 & 326 & 24.0 \\
\hline & 20 & 48 & 374 & 27.5 \\
\hline & 21 & 58 & 432 & 31.7 \\
\hline & 22 & 75 & 507 & 37.3 \\
\hline & 23 & 87 & 594 & 43.6 \\
\hline & $\overline{24}$ & 95 & 689 & 50.6 \\
\hline & 25 & 111 & 800 & 58.8 \\
\hline & 26 & 101 & 901 & 66.2 \\
\hline & 27 & 156 & 1057 & 77.7 \\
\hline & 28 & 304 & 1361 & 100.0 \\
\hline Total & & 1361 & & 100.0 \\
\hline
\end{tabular}

Note. The line separates the point at which $50 \%$ of the participants felt prepared on 24 or more of the competencies. 


\section{Rationale for Methodology}

The Multivariate Analysis of Variance (MANOVA) procedure was used to answer the three specific research question of this study. The use of MANOVA is appropriate because it is assumed the responses came from multivariate normal distribution with the dependent variables (i.e., the 28 survey items) being correlated. The MANOVA procedure capitalizes upon these correlations, and thereby enables determination for significant differences between groups on a set of dependent variables in a simultaneous manner (Stevens, 1986). The MANOVA procedure helps to reduce or control the overall Type I error, (rejection of a true null hypothesis) while at the same time being a more powerful test of significance. A MANOVA procedure has the advantage of combining small differences which in total lead to a significant difference. In the event the MANOVA procedure detects a significant difference between the groups for a set of dependent variables considered simultaneously, the univariate test of significance generated as part of the MANOVA procedure will be examined for specific statistical significance by individual dependent variable.

Three specific subsidiary research questions will further examine the data from the POP survey. They will compare different subgroups among the beginning teachers to determine significant differences and similarities of their perceived level of preparation to demonstrate the generic competencies. 


\section{Specific Research Question \#1}

Is there a significant difference in the perceived level of preparation among beginning teachers teaching in elementary, middle, and high school classrooms?

This question specifically addresses the level of preparation of responding beginning teachers at the elementary versus middle and high school levels. Statistical analysis of the data involved a comparison of the three groups. The dependent variable analyzed in Table 6 was the beginning teachers response to all 28 items representing the generic competencies.

The actual data analysis involved a comparison of the mean ratings (i.e., actual rating before recoding) for each of the identified competencies by the respondents' school level (elementary, middle, and high school). Since 28 survey items (the dependent variables) were analyzed to address this question, the researcher used the MANOVA test of significance $(\propto=.05)$.

The results indicate that beginning teachers working in the elementary schools perceived themselves better prepared to demonstrate most competency items than middle and high school beginning teachers in their preparation regarding specific competencies. The elementary beginning teachers scored higher than the middle and high school respondents on 20 competency items. The high school respondents scored the highest on five competency items and the middle scored the highest ratings on three competency items. However, middle and high school beginning teachers did not reflect any 


\section{Table 6}

Means and Standard Deviations of Degree of Preparedness by Competency for Elementary Versus Middle and High School Teachers

\section{Competency Item/}

Level

$\underline{\mathrm{n}}$

Mean

$\mathrm{SD}$

1. Match instructional strategies

to student learner needs

Elementary

Middle

High School

Total

2. Assist students in developing positive self-concepts, values, attitudes, and beliefs

Elementary
Middle

High School

Total

3. Assist students in appreciating and respecting persons from various ethnic, cultural, linguistic, and economic groups

Elementary

Middle

High School

Total

4. Arrange classroom furniture, equipment, and instructional aids to facilitate

teaching. learning, and safety
Elementary

Middle

High School

Total
779

294

197

1270
3.22

3.19

3.16

3.21
.70

.71

.75

.71
779

294

197

1270

779

294

197

1270
3.37

3.25

3.22

3.32
.77

.79

.78

.78
5. Manage situations involving severe

emotional stress

Elementary

Middle

779

294

197

1270

3.18

.88

3.01

3.04

.95

3.12

.88

.90

High School

Total

$\begin{array}{ll}3.26 & .92\end{array}$

$$
\text { Total }
$$

$\begin{array}{ll}2.51 & .92 \\ 2.64 & .93 \\ 2.60 & .91 \\ 2.55 & .93\end{array}$


6. Manage situations involving alcohol and drug abuse

Elementary

Middle

High School

Total

7. Manage situations involving child abuse and/or neglect

Elementary

Middle

High School

Total

8. Implement school rules and maintain a standard of classroom conduct

Elementary

Middle

High School

Total

9. Use verbal/non-verbal techniques, parents,

and school/community resources to

reinforce or modify student behaviors

Elementary

Middle

High School

Total

10. Determine students' entry level

knowledge/skills using diagnostic tests,

teacher observation, and student records

Elementary

Middle

High School

Total

11. Formulate long-range goals that are both consistent with state and district goals and appropriate to student needs

\section{Elementary}

Middle

High School

Total
779

1270

$\begin{array}{ll}3.18 & .84\end{array}$

2.97

2.86

2.92

2.94
.88

.94

.89

.90 
Competency Item/

Level

n

Mean

SD

12. Construct and sequence short-range

objectives for a given subject area

$\begin{array}{lr}\text { Elementary } & 779 \\ \text { Middle } & 294 \\ \text { High School } & 197 \\ \text { Total } & 1270\end{array}$

779

294

197

1270

Total

3.49

.74

.72

13. Use a variety of materials and media based upon curricular objectives, student needs, and available resources

$\begin{array}{lr}\text { Elementary } & 779 \\ \text { Middle } & 294 \\ \text { High School } & 197 \\ \text { Total } & 1270\end{array}$

$3.40 \quad .76$

14.Select/develop and sequence learning activities appropriate to instructional objectives and student learning needs

Elementary

Middle

High School

Total

15.Use class time efficiently

Elementary

Middle

High School

Total

16.Communicate effectively using verbal

and non-verbal skills to enhance

student performance

Elementary

Middle

High School

Total

17.Modify instructional strategies during learning activities based on student responses and needs

Elementary

Middle

High School

Total

18. Use student ideas, talents and products to secure interest and maintain attention

Elementary

Middle

High School

Total
779

294

197

1270

779

294

197

1270

779

294

197

1270

779

294

197

1270

779

294

197

1270
3.43

3.30

3.31

3.38

3.30

3.31

3.39

3.32

.71

.78

.70

.73

.79

.82

.76

.79

3.42

.70

3.78

.75

3.43

.69

3.41

.71

3.27

3.24

3.19

.78

.78

.73

3.25

.77

3.25

.78

3.04

.86

$3.06 \quad .83$

3.17

.81

Table continues 
19. Teach various forms of knowledge, such as concepts, laws, law-like principles, academic rules and values

Elementary

Middle

High School

1270

20. Provide directions appropriate to instructional activities, and ensure comprehension of those directions

\section{Elementary}

Middle

High School

Total

21. Use both low and high order questioning techniques to stimulate thinking and check comprehension

\section{Elementary}

Middle

High School

Total

22. Provide appropriate and varied practice activities, and monitor performance on these activities to promote learning and retention

\section{Elementary}

Middle

High School

Total

23. Show acceptance and value of student responses, and redirect digressions without devaluing student responses

Elementary

Middle

High School

Total

24. Use clear feedback (both praise and correction) to inform and help students during instruction and after assessment

\section{Elementary}

Middle

High School

Total

$\begin{array}{ll}3.40 & .73\end{array}$


Competency Item/

Mean

SD

25. Conduct systematic reviews of subject matter before, during, and after lessons

$\begin{array}{lccc}\text { Elementary } & 779 & 3.45 & .73 \\ \text { Middle } & 294 & 3.34 & .79 \\ \text { High School } & 108 & 3.67 & .73 \\ \text { Total } & 1270 & 3.41 & .75\end{array}$

26. Select/develop/modify and use a variety of assessment strategies, including classroom tests, to evaluate student progress and achievement

Elementary

Middle

779

294

3.36

.73

High School

3.33

77

$\begin{array}{lll}108 & 3.31 & .79\end{array}$

Total

1270

$\begin{array}{ll}3.34 & .75\end{array}$

27. Record and report individual and class progress

in accordance with pertinent laws and policies

$\begin{array}{lccc}\text { Elementary } & 779 & 3.05 & .91 \\ \text { Middle } & 294 & 3.13 & .92 \\ \text { High School } & 108 & 3.15 & .91 \\ \text { Total } & 1270 & 3.09 & .91\end{array}$

28. Integrate computers in instruction

Elementary

779

$\begin{array}{ll}2.73 & 1.00\end{array}$

Middle

294

2.64

1.00

High School

108

2.54

1.01

Total

1270

2.68

1.00

significant differences in their responses. Table 6 shows that their mean scores were very similar.

The Wilks lambda (Stevens, 1986) was the most appropriate test to be used as the multivariate test of significance to examine the differences in perceptions of preparation of the 28 items by school level. This test determines whether there is a significant relationship between a set of dependent variables for more than two groups (the 
independent variables) in this study, (i.e., beginning teachers from the elementary, middle and high school levels). There was a significant difference by teaching level found when all 28 items were analyzed together, Wilks=.89, $\mathrm{df}=54,2482, \mathrm{p}<.005$.

To find out how they were different, the 28 competency items were further analyzed using Univariate $\mathrm{F}$ tests. There were four significant differences found at the .05 level of significance and five at the .01 level of significance among the level of preparation of beginning teachers working in the elementary, middle, and high school levels (see Table 7).

Table 7

F Values and Significance of $F$ for Each of the 28 Competency Items Comparing Elementary Versus Middle and High School Beginning Teachers

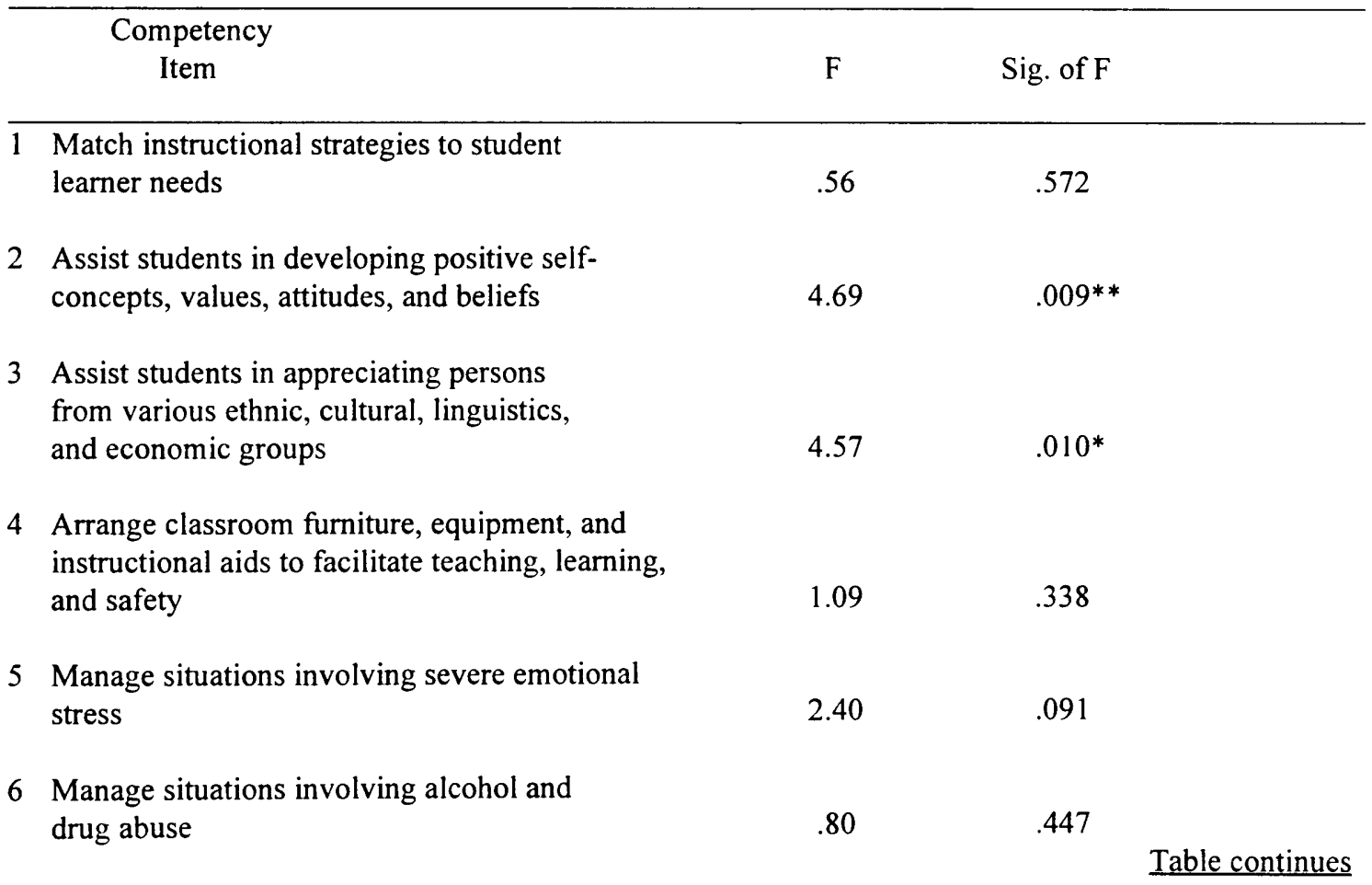




\section{Competency \\ Item}

7 Manage situations involving child abuse and/or neglect

8 Implement school rules and maintain a standard of classroom conduct

9 Use verbal/non-verbal techniques, parents, and school/community resources to reinforce or modify student behaviors

10 Determine students' entry level knowledge/skills using diagnostic tests, teacher observation, and student records

11 Formulate long-range goals that are both consistent with state and district goals and appropriate to student needs

13 Use a variety of materials and media based upon curricular objectives, student needs, and available resources

14 Select/develop and sequence learning activities appropriate to instructional objectives and student learning needs

15 Use class time efficiently

16 Communicate effectively using verbal and non-verbal skills to enhance student performance

17 Modify instructional strategies during learning activities based on student responses and needs

18 Use student ideas, talents, and products to secure interest and maintain attention

19 Teach various forms of knowledge, such as concepts, laws, law-like principles, academic rules and values 


\section{Competency Item}

F

Sig. of $\mathrm{F}$

20 Provide directions appropriate to instructional activities, and ensure comprehension of those directions

21 Use both low and high order questioning techniques to stimulate thinking and check comprehension

$.005^{* *}$

22 Provide appropriate and varied practice activities, and monitor performance on these activities to promote learning and retention

23 Show acceptance and value of student responses, and redirect digressions without devaluing student responses

24 Use clear feedback (both praise and correction) to inform and help students during instruction and after assessment .250

25 Conduct systematic reviews of subject matter before, during, and after lessons

26 Select/develop/modify and use a variety of assessment strategies, including classroom tests, to evaluate student progress and achievement

27 Record and report individual and class progress in accordance with pertinent laws and policies

28 Integrate computers in instruction

${ }^{*} \mathrm{p}<.05 . \quad{ }^{* *} \mathrm{p}<.01$

Then a discriminate analysis was used to determine which groups were significantly different on competency items. A significant difference was found between the elementary school subjects and the middle school respondents. There was also a 
significant difference between the elementary and high school respondents. There was no significant difference between the middle and high school respondents.

Further analysis of those competencies in which participants differed significantly in their perceived level of preparation involved performing post-hoc t tests to determine significant differences between elementary and middle beginning teachers and elementary and high school beginning teachers (see Tables 8 and 9).

Table 8

Means and Standard Deviation of Degree of Preparation by Competency for Elementary Versus Middle $\underline{\text { School Teachers }}$

Competency Item/

nean

SD

$\underline{\mathrm{t}} \quad \mathrm{p}$

2 Assist students in developing positive self-concepts, values, attitudes, and beliefs

Elementary
Middle

1083

3.39

$388 \quad 3.27$

.75

.77

2.55

$.011^{*}$

3. Assist students in appreciating persons from various cultural, linguistic, and economic groups

Elementary

Middle

$1081 \quad 3.18$

.87

2.78

$.006^{* *}$

13. Use a variety of materials and media based upon curricular objectives, student needs, and available resources

Elementary

Middle

14. Select/develop and sequence learning activities appropriate to instructional objectives and student learning needs Elementary

Middle

$393 \quad 3.03$

.94

$1079 \quad 3.44$

$386 \quad 3.26$

1085

387
.71

.77
.75

.82
2.53

3.78

$.0005^{* *}$

.82
7

(7)


Competency Item/

Level

$\underline{n}$

Mean

SD

$\underline{\mathrm{t}}$

$\mathrm{p}$

18. Use student ideas, talents, and products

To secure interest and maintain

attention

Elementary

Middle

$\begin{array}{ll}1080 & 3.24 \\ 388 & 3.07\end{array}$

.79

3.58

$.0005 * *$

$\begin{array}{lll}388 & 3.07 & .84\end{array}$

84

21. Use both low and high order questioning techniques to stimulate thinking and check comprehension

Elementary

Middle

1073

3.43

$\begin{array}{lll}387 & 3.31 & .78\end{array}$

.75

2.59

$.010^{* *}$

22 Provide appropriate and varied practice activities, and monitor performance on these activities to promote learning and retention

Elementary

Middle

23. Show acceptance and value of student responses, and redirect digressions without devaluing student responses

\section{Elementary}

Middle

28. Integrate computers in instruction

Elementary

Middle

$345 \quad 2.60 \quad 1.01$

${ }^{*} \mathrm{p}<.05 . \quad{ }^{* *} \mathrm{p}<.01$

In a like manner, a post-hoc t test was also conducted on elementary versus high school beginning teachers' responses concerning their preparation of the 28 competency items. Significant differences were found between the two groups for nine competencies. 


\section{Table 9}

Means and Standard Deviations of Degree of Preparation by Competency for Elementary Versus High

School Teachers

Competency Item/

Level

n

SD

$\underline{t} \quad p$

2. Assist students in developing positive self-concepts, values, attitudes, and beliefs

$\begin{array}{llllll}\text { Elementary } & 1083 & 3.39 & .75 & 2.89 & .004^{* *} \\ \text { High School } & 275 & 3.24 & .77 & & \end{array}$

3. Assist students in appreciating persons from various ethnic, cultural, and economic groups

Elementary

High School

$273 \quad 3.08$

13. Use a variety of materials and media based upon curricular objectives, student needs and available resources

Elementary

High School

269

3.44

.75

3.22

$.001^{* *}$

14. Select/develop and sequence learning activities appropriate to instructional objectives and student learning needs

Elementary

High School
18. Use student ideas, talents, and products

to secure and maintain attention

Elementary

High School

1080

273

3.24

3.10

.79

21. Use both low and high order questioning techniques to stimulate thinking and check comprehension

Elementary

High School
$1073 \quad 3.43$

$271 \quad 3.26$
.75

.78
$2.52 \quad .012^{*}$

$2.62 \quad .009^{* *}$

$3.33 \quad .001^{* *}$

Table continues 
22. Provide appropriate and varied practice activities and monitor performance on these activities to promote learning and retention

Elementary

High School
$1069 \quad 3.41$

$269 \quad 3.32$
.72

.75

23. Show acceptance and value of student responses, and redirect digressions without devaluing student responses

Elementary

High School
1073

275

1007

235
3.46

3.39

2.71

2.52

Elementary
High School

${ }^{*} \mathrm{p}<.05 . \quad{ }^{* *} \mathrm{p}<.01$.

Post-hoc $\underline{t}$ tests were not done to compare the middle versus the high school respondents since there were no significant differences found between these two groups in this discriminate analysis.

\section{Specific Research Question \#2}

Is there a significant difference in the perceived level of preparation between beginning teachers graduating from public and private colleges and/or universities?

The second question specifically addresses the level of preparation of responding beginning teachers graduating from public versus private colleges and/or universities. Statistical analysis of the data involved a comparison of the two groups. The dependent 
variables analyzed were their responses regarding the preparation of the 28 survey items representing the generic competencies.

The actual data analysis involved a comparison of the mean ratings (i.e., rating before recoding) for each of the identified competencies by type of graduating institution (private or public). The researcher used a MANOVA test of significance at the .05 level of significance.

The multivariate two-group test, the Hotellings, was the most appropriate test of significance to examine the differences in perceptions of preparation by respondents graduating from public versus private colleges and universities. This test determines whether there is a significant relationship when comparing only two groups. No significant differences between the perceived level of preparation of those graduating from public and private institutions were found to exist, Hotellings $=.97, \mathrm{df}=24,1285$, $\mathrm{p}>$.125. Consequently, no further post hoc analyses of these variables was needed.

\section{Specific Research Question \#3}

Is there a significant difference in the perceived level of preparation between beginning teachers graduating from a college/university in Florida and one outside of

\section{Florida?}

The third question specifically addresses the level of preparation of responding beginning teachers graduating from a college/university in Florida (in-state) versus one outside of Florida (out-of-state). Statistical analysis of the data involved a comparison 
between the two groups. The dependent variables analyzed were their responses to all 28 items representing the generic competencies.

The process for the analysis was done in the same manner as question one. Again, the researcher involved a comparison of the mean ratings for each of the identified competencies. The MANOVA test of significance used was at the .05 level of significance.

The Hotellings was the most appropriate test to be used as the multivariate test of significance. As in the analysis of question two, there were two groups, those graduating from in-state versus out-of-state, being compared. This test determines whether there is a significant relationship between them, Hotellings $=.06, \mathrm{df}=27,1337, \mathrm{p}<.0005$.

Since there was a significant difference between the two groups the 28 competency items were further analyzed by a Univariate F test. There were significant differences found at the .05 level for items 9 and 28, and at the .01 level for items 21,23 and 25 among the respondents graduating from in-state versus out-of-state institutions. The respondents graduating from the in-state institutions felt better prepared (see Table 10). 
Table 10

Univariate F-tests Comparing In-state Versus Out-of-state Graduating Institutions Including Means and

$\underline{\text { Standard Deviation }}$

Competency Item

n $\quad$ Mean $\quad$ SD $\quad F \quad$ Sig. of $F$

1. Match instructional strategies to student

learner needs

In-state

Out-of-state

Total

$\begin{array}{lll}1006 & 3.20 & .69\end{array}$

$\begin{array}{lll}351 & 3.22 & .76\end{array}$

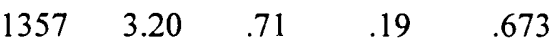

2. Assist students in developing positive self-

concepts, values, attitudes, and beliefs

In-state

$\begin{array}{lll}1006 & 3.32 & .77\end{array}$

Out-of-state

$\begin{array}{lll}351 & 3.30 & .78\end{array}$

Total

$\begin{array}{lll}1357 & 3.32 & .77\end{array}$

$.47 \quad .494$

3. Assist students in appreciating persons

from various cultural, linguistic, and

economic groups

In state

$\begin{array}{lll}1006 & 3.12 & .89\end{array}$

Out-of-state

$\begin{array}{lll}351 & 3.11 & .93\end{array}$

Total

$\begin{array}{lll}1357 & 3.12 & .90\end{array}$

$.03 \quad .871$

4. Arrange classroom furniture, equipment, and instructional aids to facilitate teaching,

learning, and safety

$$
\begin{aligned}
& \text { In-state } \\
& \text { Out-of-state } \\
& \text { Total }
\end{aligned}
$$

5. Manage situations involving severe emotional stress
In-state
Out-of-state
Total

6. Manage situations involving alcohol and drug abuse

In-state

Out-of-state

Total $\begin{array}{lll}1006 & 3.27 & .91\end{array}$

$\begin{array}{lll}351 & 3.21 & .92\end{array}$

$\begin{array}{lllll}1357 & 3.25 & .91 & .91 & .342\end{array}$

$\begin{array}{rrrrr}1006 & 2.54 & .91 & & \\ 351 & 2.62 & .93 & & \\ 1357 & 2.56 & .92 & 1.86 & .173\end{array}$


7. Manage situations involving child abuse and/or neglect

$\begin{array}{lrrrrr}\text { In-state } & 1006 & 2.75 & .92 & & \\ \text { Out-of-state } & 351 & 2.64 & .99 & & \\ \text { Total } & 1357 & 2.72 & .94 & 3.93 & .048\end{array}$

8. Implement school rules and maintain a standard of classroom conduct

$\begin{array}{lrrrrr}\text { In-state } & 1006 & 3.27 & .82 & & \\ \text { Out-of-state } & 351 & 3.24 & .83 & & \\ \text { Total } & 1357 & 3.27 & .82 & .44 & .505\end{array}$

9. Use verbal/non-verbal techniques, parents, and school/community resources to reinforce or modify student behaviors

$\begin{array}{lrrrrr}\text { In-state } & 1006 & 3.22 & .82 & & \\ \text { Out-of-state } & 351 & 3.07 & .89 & & \\ \text { Total } & 1357 & 3.18 & .84 & 8.27 & .004 * *\end{array}$

10. Determine students' entry level knowledge/ skills using diagnostic tests, teacher observation, and student records

$\begin{array}{lrrrrr}\text { In-state } & 1006 & 2.94 & .90 & & \\ \text { Out-of-state } & 351 & 2.94 & .88 & & \\ \text { Total } & 1357 & 2.94 & .89 & .00 & .995\end{array}$

11. Formulate long-range goals that are both consistent with state and district goals and appropriate to student needs

In-state

Out-of-state

Total

12. Construct and sequence short-range objectives for a given subject area

$$
\text { In-state }
$$

Out-of-state

Total $\begin{array}{lll}1006 & 3.04 & .86\end{array}$

$\begin{array}{lll}351 & 2.99 & .92\end{array}$

$\begin{array}{lll}1357 \quad 3.02 & .88\end{array}$

$.72 \quad .396$

$\begin{array}{lll}1006 & 3.50 & .72\end{array}$

$\begin{array}{lll}351 & 3.44 & .75\end{array}$

$\begin{array}{lllll}1357 & 3.48 & .73 & 1.63 & .202\end{array}$

Table continues 
13. Use a variety of materials and media based upon curricular objectives, student needs and available resources

In-state

Out-of-state

Total

14. Select/develop and sequence learning activities appropriate to instructional objectives and student learning needs

In-state
Out-of-state
Total

15. Use class time efficiently

In-state

Out-of-state

Total

16. Communicate effectively using verbal and non-verbal skills to enhance student performance
In-state
Out-of-state
Total

17. Modify instructional strategies during learning activities based on student responses and needs

In-state
Out-of-state
Total

18. Use student ideas, talents and products to secure interest and maintain attention
In-state
Out-of-state
Total

$\begin{array}{rrrrr}1006 & 3.38 & .79 & & \\ 351 & 3.41 & .72 & & \\ 1357 & .339 & .77 & .36 & .548\end{array}$

$\begin{array}{lll}1006 & 3.38 & .74\end{array}$

$\begin{array}{lll}351 & 3.33 & .73\end{array}$

$\begin{array}{lll}1357 & 3.37 & .74\end{array}$

$.95 \quad .331$

$\begin{array}{rrrrr}1006 & 3.33 & .80 & & \\ 351 & 3.32 & .78 & & \\ 1357 & 3.33 & .79 & .01 & .917\end{array}$

$\begin{array}{lll}1006 & 3.42 & .69\end{array}$

$\begin{array}{lll}351 & 3.35 & .75\end{array}$

$\begin{array}{lllll}1357 & 3.41 & .71 & 3.46 & .063\end{array}$

$\begin{array}{lll}1006 & 3.24 & .78\end{array}$

$\begin{array}{lll}351 & 3.25 & .76\end{array}$

$\begin{array}{lllll}1357 & 3.24 & .77 & .09 & .768\end{array}$

$\begin{array}{lll}1006 & 3.19 & .81\end{array}$

$\begin{array}{lll}351 & 3.13 & .80\end{array}$

$\begin{array}{lllll}1357 & 3.18 & .81 & 1.63 & .202\end{array}$

19. Teach various forms of knowledge, such as concepts, laws, law-like principles, academic rules and values
In-state
Out-of-state
Total

$\begin{array}{lll}1006 & 3.22 & .82\end{array}$

$\begin{array}{lll}351 & 3.17 & .82\end{array}$

$\begin{array}{lll}1357 & 3.20 \quad .82\end{array}$

$.99 \quad .390$

Table continues 
20. Provide directions appropriate to instructional activities, and ensure comprehension of those directions

In-state

Out-of-state

Total

21. Use both low and high order questioning techniques to stimulate thinking and check comprehension
In-state
Out-of-state

Total

22. Provide appropriate and varied practice activities, and monitor performance on these activities to promote learning and retention

$$
\begin{aligned}
& \text { In-state } \\
& \text { Out-of-state } \\
& \text { Total }
\end{aligned}
$$

23. Show acceptance and value of student responses, and redirect digressions without devaluing student responses

In-state
Out-of-state
Total

24. Use clear feedback (both praise and correction) to inform and help students during instruction and after assessment

In-state
Out-of-state
Total

25. Conduct systematic reviews of subject matter before, during, and after lessons

In-state
Out-of-state
Total

$\begin{array}{rrrrr}1006 & 3.42 & .73 & & \\ 351 & 3.37 & .73 & & \\ 1357 & 3.41 & .73 & 1.00 & .318\end{array}$

$\begin{array}{lll}1006 & 3.41 & .76\end{array}$

$\begin{array}{lll}351 & 3.31 & .76\end{array}$

$\begin{array}{lllll}1357 & 3.39 & .76 & 5.00 & .025 *\end{array}$

$\begin{array}{rrrrr}1006 & 3.42 & .72 & & \\ 351 & 3.31 & .75 & & \\ 1357 & 3.39 & .73 & 3.95 & .047\end{array}$

$\begin{array}{lll}1006 & 3.44 & 75\end{array}$

$\begin{array}{lll}351 & 3.33 & .77\end{array}$

$\begin{array}{lllll}1357 & 3.41 & .76 & 5.40 & .020^{*}\end{array}$

$\begin{array}{rrrrr}1006 & 3.47 & .72 & & \\ 351 & 3.40 & .73 & & \\ 1357 & 3.45 & .73 & 2.67 & .103\end{array}$

$\begin{array}{rrrrr}1006 & 3.42 & .75 & & \\ 351 & 3.31 & .76 & & \\ 1357 & 3.39 & .76 & 5.44 & .020^{*}\end{array}$


26. Select/develop/modify and use a variety of assessment strategies, including classroom tests, to evaluate student progress and achievement

In-state
Out-of-state
Total

1006

351

1357

$\begin{array}{ll}3.34 & .75 \\ 3.33 & .75 \\ 3.34 & .75\end{array}$

$.02 \quad .904$

27. Record and report individual and class progress in accordance with pertinent laws and policies

In-state
Out-of-state
Total

28. Integrate computers in instruction

In-state

Out-of-state

Total

$\begin{array}{rrrrr}1006 & 3.09 & .89 & & \\ 351 & 3.13 & .93 & & \\ 1357 & 3.10 & .90 & .53 & .468\end{array}$

$\begin{array}{lll}1006 & 2.73 & .98\end{array}$

$\begin{array}{lll}351 & 2.48 & 1.08\end{array}$

$\begin{array}{lllll}1357 & 2.67 & 1.01 & 16.57 & .000^{* *}\end{array}$

${ }^{*} \mathrm{p}<.05 . \quad{ }^{* *} \mathrm{p}<.01$

The output of MANOVA procedure also generated descriptive statistics (means and standard deviations) for the two levels of independent variables, in-state and out-of-state graduates, for each of the competency items. Examination of the descriptive statistics for each of the five competency items found to be significantly different in the MANOVA reveals that in-state graduates felt better prepared than out-of-state graduates (see Table $11)$. 
Table 11

Means and Standard Deviations for Competencies with Significant Differences for In-state and Out-of-state

Graduating Institutions

Competency Item/

n $\quad$ Mean

SD

In/Out-of-State

9. Use verbal/non-verbal techniques, parents, and /community resources to reinforce or modify student behaviors

$\begin{array}{lccc}\text { In-state } & 1006 & 3.22 & .82 \\ \text { Out-of-state } & 351 & 3.07 & .89 \\ \text { Total Sample } & 1357 & 3.18 & .84\end{array}$

21. Use both low and high order questioning techniques to stimulate thinking and check comprehension

In-state

Out-of-state

Total Sample

23. Show acceptance and value of student

responses, and redirect digressions

without devaluing student responses

In-state

Out-of-state

Total Sample

25. Conduct systematic reviews of subject matter

before, during, and after lessons

In-state

1009

356

Out-of-state

1365

Total Sample

28. Integrate computers in instruction

In-state

1009

356

Out-of-state

1365

Total Sample

1009

356

1365

356
3.41

3.31

3.39

.76

.76

.76

3.44

.75

3.33

.77

3.41

.76

84

3.41

.82

84




\section{CHAPTER V}

Summary, Discussion, Conclusions, and Recommendations

This Chapter is divided into four main parts. First the study will be briefly

summarized. Second, each of the research questions and findings are discussed. Third, conclusions drawn from the study are presented and lastly recommendations for the profession and future research are discussed.

\section{$\underline{\text { Summary }}$}

Among the educational challenges facing Florida is to respond to Blueprint 2000 "one of the most comprehensive and dramatic reforms of a state system of public schools in our nation's history" (Florida Commission on Education Reform and Accountability, 1994, p. 2). Florida is in the midst of a school improvement movement which includes the identification of generic knowledge skills and dispositions needed by teachers. The Education Standards Commission (ESC) has been working diligently to identify and validate accomplished teacher practices necessary to comply with Blueprint 2000 . This study supports the work of the Commission by analyzing the perceived degree of preparation for each of Florida's current Essential Generic Competencies as reflected in the results of a survey completed by beginning teachers who finished the POP during 1992-93. In addition, teacher education units need to evaluate their teacher preparation programs to meet program approval and accreditation requirements of the Department of Education, Board of Regents, the Southern Accreditation of Colleges and Schools, and 
for some the National Council for Accreditation of Teacher Education. The generic competencies examined in the study form part of the DOE standards which must be met by programs in order to receive program approval.

The review of the literature presents a brief summary of proposed national reforms in teacher preparation like the reports Time for Results (National Governor's Association, 1986); Tomorrow's Teachers (Holmes Group, 1986), and A Nation Prepared: Teachers for the 21st Century (Carnegie Forum, 1986). Although these reports do not necessarily advocate competency-based teacher preparation, their recommendations are relevant to this study because they discuss the improvement of teacher preparation standards. The review also includes historical highlights of the national and state competency-based movement.

The final part of the review of the literature presents two follow-up studies of beginning teachers dealing with the perception of beginning teachers regarding their teacher education preparation. Oguntade's (1983) study indicated that beginning teachers in Florida perceived their preparation as adequate in most of the teaching competencies. Both Oguntade's (1983) and the present study found that the following competency received a very low preparation rating. The competency reads: Assist students in appreciating and respecting persons from various ethnic, cultural, linguistic, and economic groups. Also, both studies found high level of perceived preparation in the area of: communicating effectively using verbal and non-verbal skills to enhance student performance. 
Eight years later, Drummond (1991) conducted a similar study to determine how beginning teachers evaluated preservice teacher education and performance. There were similarities between the results of his study and the present one. They will be thoroughly discussed later in this chapter.

This study analyzes self-reported survey data collected in January, 1993 from graduates of 29 Florida teacher education programs. There were 5,076 beginning teachers who received the Professional Orientation Survey (POP) of which 1,995 completed and returned it. The instrument was developed in collaboration with the Department of Education, the members of the Florida Association of Colleges of Teacher Education, and the Professional Orientation Program (POP) coordinators. The Project Director of Program Review in the College of Education at the University of South Florida coordinated the development and administration of the survey.

While the survey consisted of four parts, the section from the survey used for this study consisted of 28 competency items rated by the respondents to indicate their perceived degree of professional preparation. Participants returned the surveys to their district POP coordinators who sent them to the Evaluation and Testing Office at the University of South Florida. Completed surveys were entered into a computer file suitable for data analysis and a copy of the original file was sent to this researcher for use in this study.

The Multivariate Analysis of Variance (MANOVA) procedure was used to answer the research questions. Significance at the .05 level was detected between the groups 
(beginning teachers) for a set of dependent variables (teaching level, kind of graduating institution) considered simultaneously. The univariate test of significance generated as part of the MANOVA procedure was examined for specific statistical significance by individual dependent variable.

\section{Discussion of Research Questions and Findings}

The answer to the major research question: How well do beginning teachers perceive their degree of preparation to demonstrate the Florida Essential Generic Competencies? is illustrated in Table 4. It shows the mean, standard deviation, and percentage of preparation for each competency. All competency statements were clustered within five categories from the highest to the lowest percentage of preparation. Each category represents $10 \%$ intervals. Category I lists the three competencies which were rated with the highest preparation scores by $90 \%$ and above by all beginning teachers who participated in the study. Those competencies were: First, to construct and sequence short-range objectives for a given subject area; second, to communicate effectively using verbal and non-verbal skills to enhance student performance; and third, to use clear feedback (both praise and correction) to inform and help students during instruction and after assessment.

Two possible reasons for the top-ranking competency may be: (1) every teacher preparation program in Florida includes methods courses and internships where written objectives are thoroughly covered for each subject area, (2) textbooks used by teachers, 
$\mathrm{K}-12$, always include short-term goals for lessons and units of all subject areas. Two of the three competencies within Category I seem to be related to communication with students. Respondents seem to be confident about this skill. Oguntade's (1983) study discussed in Chapter II reported similar findings. The areas of greatest strength found by Oguntade (1983) and Drummond (1991) were communication skills and teaching methods which included communication skills such as: sequencing objectives, listening, and reading comprehension, written and oral communication.

Category II includes 16 competency statements that $80 \%$ to $89 \%$ of the participants felt adequately prepared to demonstrate. Even though many of the competencies are included in this category, there is no pattern or unifying principle within this cluster. Interestingly, $82 \%$ of the beginning teachers felt prepared in the area of maintaining classroom conduct, a competency often rated lower by beginning teachers.

Category III includes four competency statements in which between $70 \%$ to $79 \%$ indicated they were prepared. They are:

Arrange classroom furniture, equipment, and instructional aids;

Record and report individual and class progress;

Assist students in appreciating and respecting persons from various ethnic, cultural, linguistic, and economic groups; and

Formulate long-range goals.

Two of these categories are related to daily routines in the classroom. These are the kind of competencies that will improve with experience. Arranging furniture and record 
keeping techniques should be practiced during internships but many times classroom teachers do not allow university students to disrupt their classrooms by moving furniture or equipment.

The third competency in this cluster has often been sited as a weakness for teacher education programs by the Florida Department of Education program approval team members. This competency needs to be better presented in the curriculum throughout the state. A course in multicultural education may not be the best way to learn the application of this competency. For teachers to appreciate and respect persons from the various ethnic, cultural, linguistic, and economic groups, there should be an attitude permeating all the courses and experiences available to students.

Category IV includes one competency which $60 \%$ to $69 \%$ of the respondents indicated they were prepared to demonstrate. This category deals with determining students' entry level knowledge/skills using diagnostic tests, teacher observation, and student records. Method and evaluation courses should prepare future teachers with this competency. Beginning teachers may be better prepared to demonstrate this competency than they realize. They may be afraid to misplace students in the wrong level. Practicing this skill may make them feel more competent.

Category V includes four competencies in which $50 \%$ to $59 \%$ of the respondents felt prepared to demonstrate. This category includes:

1. Integrate computers in instruction.

2. Manage situations involving child abuse and/or neglect. 
3. Manage situations involving severe emotional stress.

4. Manage situations involving alcohol and drug abuse.

Three of the competencies in this category are very similar. They relate to the child's physical and mental well-being. When beginning teachers are hit with the reality of the classroom versus case studies discussed in texts, they are frightened. Again, years of experience will offer the best preparation to deal with these kinds of situations. However, the student teaching experience should provide opportunities where the future teachers could work with students identified as having such problems. On the other hand, the competency about using technology in the classroom should have a much higher rating of preparation. This competency should be introduced and practiced in several courses during the teacher preparation program. Teachers will not be able to integrate computers in instruction by taking only one course. Computer skills should be incorporated in method courses for elementary, middle, and high school teachers.

Categories IV and V include the five lowest rated competency statements. With the exception of the one that deals with managing situations involving severe emotional stress the other four match Drummond's (1991) lowest rated competencies. These findings support Drummond's study.

The Florida Essential Generic Competencies are included in the curriculum of all teacher preparation programs throughout the state of Florida. Joint Review Teams look for evidence of their inclusion in appropriate courses as a prerequisite for state program approval. If there is no evidence that these competencies are taught in the curriculum, the 
Joint Review Team will cite weaknesses and standards not met. In some instances, they may not approve the program for teacher certification. The findings of this study indicate that teacher preparation programs need to focus on the lowest rated competencies (Categories II, III, IV, and V) to strengthen their curricula.

Additional analyses of the data related to the major research question were conducted. Table 5 illustrates the number of competencies that each respondent felt prepared to demonstrate. Only $50 \%$ of the respondents felt that they were prepared to demonstrate up to 24 of the 28 competency items presented in the survey. These data should be of concern to teacher preparation programs. One would expect a much lower percentage of respondents feeling unprepared to demonstrate most of the competencies.

The first specific research question answered by this study reads, Is there a significant difference in the perceived level of preparation among beginning teachers in elementary, middle, and high school classrooms?

Table 8 shows the eight competency items in which significant differences between the elementary and the middle school level teachers perceived preparation. They were:

$\underline{\text { Item }}$

2

3

13

\section{Competency}

Assist students in developing positive self-concepts, values, attitudes and beliefs.

Assist students in appreciating and respecting persons from various ethnic, cultural, linguistic, and economic groups.

Use a variety of materials and media based upon curricular objectives, student needs, and available resources. 
Select/develop and sequence learning activities appropriate to instructional objectives and student learning needs.

Use student ideas, talents, and products to secure interest and maintain attention.

Use both low and high order questioning techniques to stimulate thinking and check comprehension.

Provide appropriate and varied practice activities and monitor performance on these activities to promote learning and retention.

Show acceptance and value of student responses, and redirect digressions without devaluing student responses.

Table 9 displays the six competency items in which significant differences between the elementary and high school level teachers perceived preparation. They were:

Item

Competency

2

Assist students in developing positive self-concepts, values, attitudes and beliefs.

Use a variety of materials and media based upon curricular objectives, student needs, and available resources.

14

Select/develop and sequence learning activities appropriate to instructional objectives and student learning needs.

18

Use student ideas, talents, and products to secure interest and maintain attention.

Use both low and high order questioning techniques to stimulate thinking and check comprehension.

The mean for the elementary respondents was not only higher than middle and high school beginning teachers for all eight competency items showing significant differences, but for a total of 20 competency items. The high school respondents scored the highest 
on five items and the middle school respondents scored the highest on three items. However, middle and high school beginning teachers did not reflect any significant differences in their responses.

There may be several reasons why the elementary teachers feel better prepared than the middle and high school beginning teachers. There is a distinct difference between the teacher preparation programs for elementary versus middle and high school teachers. Elementary education programs throughout the state of Florida have a required methods courses for the different subject areas since elementary teachers are usually responsible for the instruction of all subjects in the elementary classroom. Middle and high school teachers as a rule only take a generic and a specialized methods course while most of their required courses are in the subject area of their majors. All State of Florida approved teacher preparation programs (elementary, middle, and high school) include a core of professional studies courses responsible for covering many of the Florida Essential Generic Competencies. The elementary courses are usually taught within the colleges of education while most of the middle and high school courses are taught in Arts and Sciences. The courses taught in Arts and Sciences have the subject matter as their major emphasis. The courses taught in colleges of education place more emphasis on teaching methods. Methods courses as opposed to content courses usually include internships where students are given the opportunity to observe and work in classrooms. Consequently, some teacher preparation programs for middle and high school students do 
not have as many pre-student teaching internship experiences because of fewer method courses required.

Another reason for the difference in the perception of preparation between the elementary, middle, and high school may be the organizational differences among the levels. The importance of the classroom environment may not be emphasized in courses for middle and high school teachers. Usually middle and high school teachers work with different groups for only one hour a day. Elementary teachers usually spend longer periods of time with the same group of students. Therefore, they may feel better prepared to create a supportive classroom atmosphere.

Elementary teachers may spend more time planning their lessons because they are responsible for the instruction of all subjects. Also, elementary teachers need to spend more time on direct instruction because their students are younger than those in middle and high school classes. Even though cooperative learning strategies are practiced in the elementary classrooms, younger students may still need more assistance than middle and high school students.

Even though there was no significant difference found among the groups, elementary teachers felt better prepared to manage situations of abuse and/or neglect. Maybe because they have more contact with the students and their parents than middle and high school teachers. For example, a competency like using verbal and non-verbal techniques, parents, and school/community resources, may be more applicable to elementary teachers. Both of these assumptions may be good topics for further research to identify 
possible reasons for differences in the responses among elementary, middle, and high school teachers.

The second specific research question reads: Is there a significant difference in the perceived level of preparation between beginning teachers graduating for Florida public and private colleges and/or universities? The Hotellings multivariate of significance was used to examine the differences in perceptions of preparation between these two groups. No significant differences were found between those graduating from public and private institutions.

One reason for the results may be that both private and public institutions in Florida follow the same standards for state program approval of their teacher preparation programs. They must submit their program folios to the Department of Education for review. Members of the DOE staff and other professionals, visit the teacher preparation units for both the private and public institution to complete the review. Evidence of instruction in the generic competencies is sought by the site visit team.

The third specific question reads: Is there a significant difference in the perceived level of preparation between beginning teachers graduating from a college/university instate versus out-of-state? Table 10 indicates that there was a significant difference in five of the 28 competency items between graduates of in-state versus out-of-state institutions. Table 11 shows that the in-state graduates had higher means for all five competencies showing a significant difference. They felt better prepared to demonstrate the following competency items: 
Use verbal/non-verbal techniques, parents, and school/community resources to reinforce or modify student behaviors. stimulate thinking and check comprehension.

Show acceptance and value of student responses, and redirect digressions without devaluing student responses.

Conduct systematic reviews of subject matter before, during, and after lessons.

Integrate computers in instruction.

It is understandable that competency item number 9 would be rated higher by in-state graduates since it includes the "use of parents and school/community resources." They would be more familiar with community resources than those coming from outside the state. Assignments relating to the use of community resources are often given during their teacher preparation programs. Consequently, by the time graduates start teaching they have already used school/community resources and may have worked with parents in the different communities served by the local schools.

Competency item number 23 includes "acceptance and value of student responses." Many times graduates from out of state have not had the opportunity to work with students from a wide variety of ethnic and cultural backgrounds like the ones represented in many of the Florida schools. Consequently, graduates from in-state institutions may 
have a better understanding of students representing different ethnic and cultural backgrounds.

Competency item number 28 , "integrate computers in institutions" was also rated higher by in-state graduates. Special attention has been given to this competency in Florida. Florida schools where students do their internship and student teaching are very often well equipped with computers for teachers' and students' use. Special technology grants awarded to school districts throughout Florida have emphasized the use of technology for all students at all levels. Florida schools have designed programs including in-service teacher training to integrate the use of computers in the classroom.

\section{$\underline{\text { Conclusion }}$}

The findings of this study indicated that more than $50 \%$ of beginning teachers who participated in the study perceived their degree of preparation as adequate for more than 24 of the 28 competency items presented in the POP survey. Also, there were four competency items that fell within Category $\mathrm{V}$ which less than $56 \%$ of the beginning teachers felt prepared to demonstrate in their classrooms. Those four competencies dealt with: integrating computers in instruction and managing situations involving child abuse and/or neglect, severe emotional stress, alcohol and drug abuse.

The findings of the present study support those of Drummond (1991) who has conducted extensive studies on the Florida Essential Generic Competencies. Both studies 
concluded that the competencies mentioned above are among the lowest rated competencies by beginning teachers.

Elementary beginning teachers felt better prepared than did middle and high school beginning teachers to demonstrate those competencies (where significant differences were found). There were no differences between those who graduated from private and public institutions in their perception of preparation to demonstrate the generic competencies. Finally, this study found that the in-state graduates felt better prepared to demonstrate the generic competencies than the out-of-state graduates (whenever significant differences were found between the two groups).

It may be concluded from these findings that the Florida institutions are doing an adequate job in preparing their graduates to demonstrate most of the generic competencies. However, special attention should be given to Categories III, IV, and V which less than $80 \%$ of beginning teachers who participated felt prepared to demonstrate.

As stated in Chapter III, chi-square goodness of fit tests were used to examine the similarity of the proportion of subjects in the sample and the population on variables of gender and ethnicity. The conclusion from these results is that the sample was not completely representative of the general population of beginning teachers for those two variables.

\section{$\underline{\text { Recommendations }}$}

Based on the findings of this study, the following recommendations are made: 
1. Florida's private and public institutions responsible for teacher education programs should increase emphasis on those generic teaching competencies that relate to integrating computers in instruction and the managing of situations involving child abuse, neglect, severe emotional stress, alcohol, and drug abuse. For example, the teacher education programs need to provide more opportunities for students to work in situations with abused children, drug abusers, and young persons with emotional problems. Community agencies dealing with those problems may develop partnerships with the institutions where the students may go as volunteers or to do internships for credit.

2. Districts should provide an orientation program for those beginning teachers who have graduated from out-of-state institutions. This experience should provide them an opportunity to become familiar with the ethnic composition and resources found in the communities where they will be teaching.

3. The Florida Department of Education (DOE) should assess the appropriateness of the Florida Essential Generic Competencies as they relate to the different levels of teaching instruction. Are the same competencies relevant for elementary, middle, and high school teachers? The answer to this question may impact the development of future competencies affecting program approval procedures, requirements in the Professional Orientation Program, and the professional education portion of the Florida Teacher Certification Examination. 
4. The survey used in this study should be conducted annually statewide. The instrument has high reliability and the use of the data could be of great value to the institutions for program evaluation.

5. A follow-up study needs to be done in which a sample of beginning teachers are identified and interviewed regarding their perception of preparation.

6. Future studies may use the other sections of the survey: Perspectives on the Program; Perspectives on the Profession; and the Perceptions of Successful Demonstration of the Competencies and the comments to ascertain additional information of teacher preparation in Florida. Each one of these sections could generate data to improve programs. 


\section{REFERENCES}

American Association of Colleges for Teacher Education, (1985). A call for change in teacher education. Washington, DC: Author.

Association of Teacher Educators (1986). Visions of reform: Implications for the education profession. Reston, VA: Author.

Atkin, J. M. (1975). Professional leadership and PBTE. In Ralph A. Smith (Ed.), Regaining educational leadership: Critical essays on PBTE/CBTE, behavioral objectives and accountability (pp. 15-23). John Wiley \& Sons, Inc.

Boguslaw, R. (1977). The new utopians: A study of system design and social change. Englewood Cliffs, NJ: Prentice-Hall.

Bowers, C.A. (1977). Emergent ideological characteristics of educational policy in Teachers College Record. Vol. 79, No. 1.

Broudy, H.S. (1975). Do they mean what they say? In Ralph A. Smith (Ed.), Regaining educational leadership: Critical essays on PBTE/CBTE, behavioral objectives and accountability (pp. 24-35). John Wiley \& Sons, Inc.

Callahan, R.E. (1962). Education and the cult of efficiency: A study of social forces that have shaped the administration of the public schools. Chicago: University of Chicago Press.

Capie, W., Anderson, S., Johnson, C., \& Ellet, C. (1979). Teacher performance assessment instruments: A handbook for interpretation. Atlanta, GA. Georgia Department of Education. 
Carnegie Forum on Education and the Economy, Task Force on Teaching as a Profession, (1986). A nation prepared: Teachers for the 21 st century. New York:

Author.

Clark, D.L., \& McNergney, R.F. (1990). Governance of Teacher Education. Handbook of research on teacher education. Association of Teacher Educators: Macmillan Publishing Company.

Drummond, R.J. (1991). Beginning teachers: What they have to say about their performance and preparation. Reports-Research Technical, University of North Florida, Educational Services and Research, College of Education and Human Services, University of North Florida, Jacksonville, FL.

Elam, S. (1971). Performance based teacher education. American Association of Colleges for Teacher Education. Washington, DC.

Feiman-Nemser, S. (1990). Teacher preparation: Structural and conceptional alternatives. In W. Robert Houston (Ed.), Hand book of research on teacher education: A project of the association of teacher educators. New York: Macmillan Publishing Company.

Florida Commission on Education Reform and Accountability (1994). Blueprint 2000: A system of school improvement and accountability 1995-96 school improvement plans. Tallahassee, Florida.

Florida Department of Education (1992). Professional Orientation Program Policies and Procedures Manual. Tallahassee, Florida. 
Florida Education Standards Commission (1994). Educator Accomplished Practices:

Knowledge, skills and dispositions needed by teachers and staff to

effectively implement Blueprint 2000. Tallahassee, Florida.

Gay, L. (1992). Educational research: Competencies for analysis and application. New

York: Macmillan Publishing Company.

Green, T. (1971). The activities of teaching. New York: McGraw Hill.

Hahn, R. (1992). The state of federal health statistics of racial and ethnic groups. Journal of the American Medical Rehabilitation. 267, 268-271.

Harnett, A., \& Naish, M. (1980). Technicians or social bandits? Some moral and political issues in the education of teachers. In P. Woods (Ed.), Teacher strategies, (pp. 254-274). London: Croom Helm.

Hertzberg, H.W. (1976). Competency based teacher education: Does it have a past or a future? Teachers College Record, 79, 1-21.

Holmes Group (1986). Tomorrow's teachers. East Lansing, MI: Author.

Houston, W. R. (1974). Competency-based education: Exploring competency-based education. Berkeley, CA: McCutcheon Publishing Corporation.

Houston, W.R., \& Howsam, R. B. (1972). Competency-based teacher education progress, problems, and prospects. Chicago: SRA.

Johns, R.L., \& Morphet, E. (1975). The economics and financing of education: A systems approach. (3rd. Ed.). New Jersey: Prentice-Hall. 
Joyce, B.R. (1975). Conceptions of man and their implications for teacher education. In

K. Ryan (Ed.) Teacher education (74th yearbook of the National Society for the

Study of Education, Part II, pp. 111-145). Chicago: University of Chicago Press.

Joyce, B.R., \& Harootunian, B. (1967). The structure of teaching. Science

Research Association. Chicago, IL

Kennedy, M. (1987). Inexact sciences: Professional education and the development of expertise. In E. Rothkopf (Ed.), Review of Research in Education (Vol. 14, pp. 133167). Washington, DC: American Educational Research Association.

Kirk, D. (1986). Beyond the limits of theoretical discourse in teacher education:

Towards a critical pedogogy. Teaching and Teacher Education, 2, 155-167.

National Council for Accreditation of Teacher Education, (1987). NCATE standards, procedures, and policies for the accreditation of professional education units: The accreditation of professional education units for the preparation of professional school personnel at basic and advance levels. Washington, DC: Author.

National Governor's Association, (1986). Time for results: The governors' report on education. Washington, DC: Author. 
Oguntade, B.L. (1983). Perceptions of Beginning Teacher Program Participants

Regarding Adequacy of preservice preparation and frequency of utilization of Florida generic teaching competencies. The Florida State University College of Education. A dissertation submitted to the Department of Educational Leadership in partial fulfillment of the requirements for the degree of Doctor of Philosophy.

Osborne, I.C. (1988). A Comparative Study of Beginning Teachers' and Support Staffs' Perception of the Florida Beginning Teacher Program. A dissertation submitted to the Department of Educational Leadership in partial fulfillment of the requirements for the degree of Doctor of Philosophy. The Florida State University, Hollie Thomas, Major Professor.

Perry, C. (1973). The short and glorious history of organizational theory. In Organizational Dynamics.

Rickover, H.G., (1963). American education - a natural failure. New York: E.P. Dutton \& Co.

Sanders, T. (1994). A New Model for Quality Assurance in Teacher Preparation. The Newsletter of the National Council for Accreditation of Teacher Education. Winter, 1994, 3, 2.

Shulman, L. (1989). Knowledge and Teaching Foundation of the New Reform. Harvard Educational Review, 57, 1.

Smith, B.O. (1969). Teachers for the real world. Washington, DC: American Association of Colleges for Teacher Education. 
Smith, B.O. (1980). A design for a school of pedagogy. Washington, DC: U.S. Government Printing Office.

Smith, P. (1975). Instructional objectives and observable behavior. In Ralph A. Smith (Ed.), Regaining educational leadership: Critical essays on PBTE/CBTE, behavioral objectives and accountability (pp. 75-86). John Wiley \& Sons, Inc.

Stevens, J. (1986). Applied Multivariate Statistics for the Social Sciences. Lawrence Erlbaum Associates, Inc. Publishers, Hillsdale, New Jersey.

Truesdell, L.A.M. (1978). A comparison of teacher perceptions of generic teaching skills for early childhood and elementary classroom teachers. A dissertation submitted to the Department of Childhood, Reading and Special Education in partial fulfillment of the requirements for the degree of Doctor of Philosophy, Florida State University College of Education.

Turlington, R.D. (1982). Focus on public education in Florida The Annual Report of the commissioner of education.

Weber, W., Cooper, J., Houston, R.W. (1973). A guide to competency based teacher education. Westfield, Texas: Competency-Based Instructional Systems, 1973.

Zeichner, K.M. (1983). Alternative paradigms of teacher education. Journal of Teacher Education, 34(3), 3-9.

Zimpher, N., \& Howey, K. (1987). Adapting supervisory practice to different orientation of teaching competence. Journal of Curriculum and Supervision, 2 (2), 101-127. 


$$
95
$$


APPENDIX A

Matrix Alligning Blueprint 2000 Standards, Generic Competencies, and INTASC 


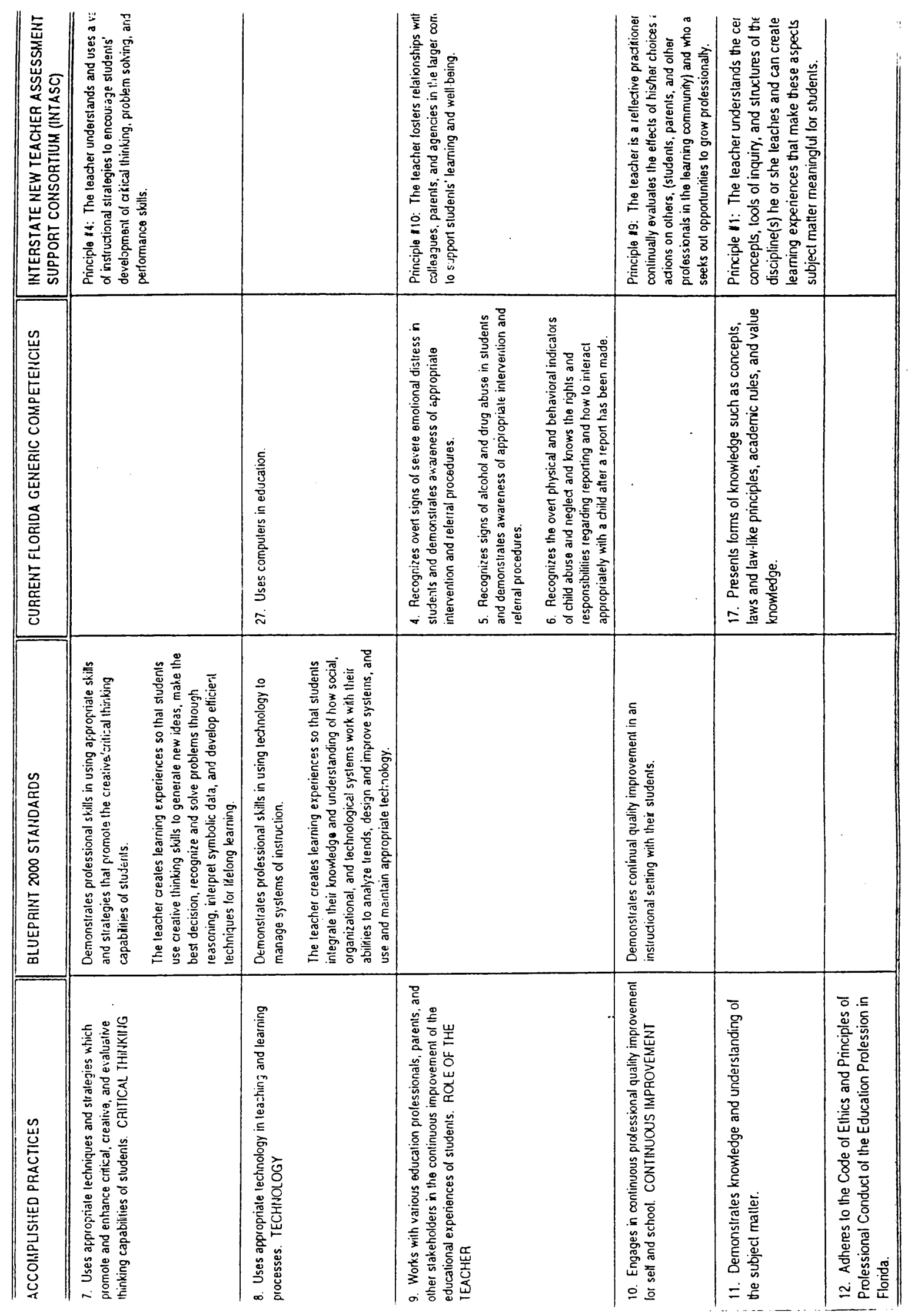




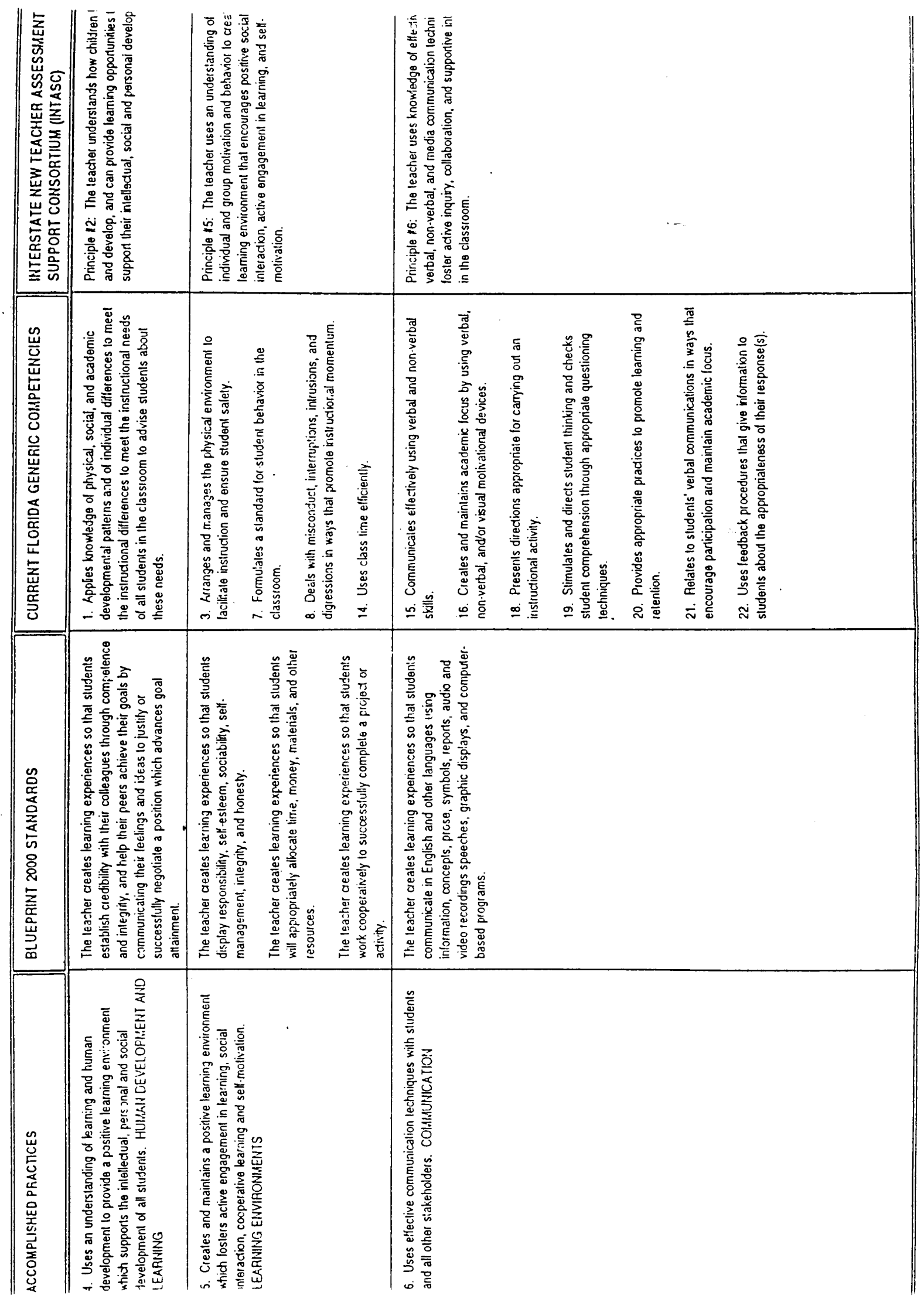




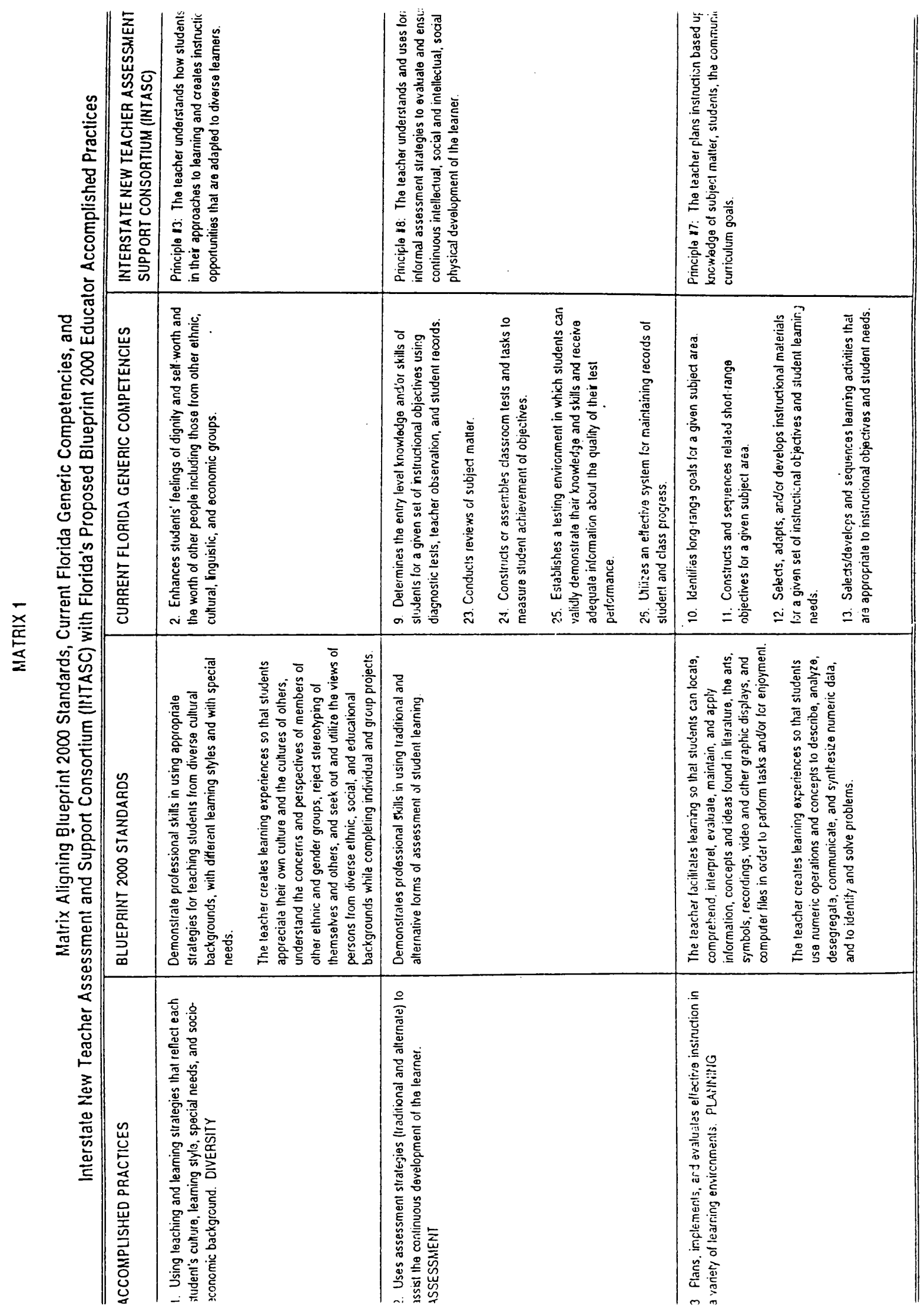




\section{APPENDIX B}

Florida Essential Generic Competencies 
1 Applies knowledge of physical, social, and academic developmental patterns and of individual differences to meet the instructional needs of all students in the classroom and to advise students about those needs.

1. Recognizes patterns of physical, social, and academic development of students in the classroom including those with exceptionalities.

2. Obtains knowledge of students through tests, observations, and student records and interprets the information to students, parents, and other appropriate personnel.

3. Demonstrates a knowledge of motivational factors or conditions which encourage students to be achievement oriented and goal directed.

4. Demonstrates knowledge of school and community resources for students who have special needs.

5. Matches learner needs with instructional elements.

2 Enhances students' feelings of dignity and self-worth and the worth of other people including those from other ethnic, cultural, linguistic, and economic groups.

1. Demonstrates instructional inter-personal skills which assist students in developing a positive self-concept.

2. Demonstrates instructional and inter-personal skills which assist students in interacting constructively with their peers.

3. Demonstrates teaching skills which assist students in developing their own values, attitudes, and beliefs.

4. Demonstrates knowledge of similarities and differences among various ethnic, cultural, linguistic, and economic groups.

5. Demonstrates teaching behaviors which assist students in developing appreciation and respect for persons from various ethnic, cultural, linguistic, and economic groups.

6. Assists students in development of short-term and long-range personal and academic goals.

3 Arranges and manages the physical environment to facilitate instruction and ensure student safety.

1. Identifies physical elements and arrangements in the classroom that directly affect learning and/or safety.

2. Arranges classroom furniture, equipment, and instructional aids to facilitate teaching, learning, and safety.

3. Organizes an effective system for placement and distribution of materials in the classroom.

4. Identifies appropriate procedures for movement of students in emergencies that can be anticipated. 
4 Recognizes overt signs of severe emotional distress in students and demonstrates awareness of appropriate intervention and referral procedures.

1. Knows and can distinguish between typical behavior and severe emotional distress in students.

2. Recognizes overt indicators of severe emotional stress, including behaviors typical of those who attempt or commit suicide.

3. Recognizes intervention techniques that are appropriate for students whose overt behavior indicates severe emotional distress.

4. Knows and utilizes resources and procedures for referral of students.

5 Recognizes signs of alcohol and drug abuse in students and demonstrates awareness of appropriate intervention and referral procedures.

1. Recognizes overt behaviors that may indicate a tendency toward the use of drugs and/or alcohol by students.

2. Recognizes physical and behavioral characteristics of students who are under the influence of drugs and/or alcohol.

3. Uses immediate referrals when any student is suspected of using drugs or alcohol to secure appropriate assistance for the suspected of fender and to protect other students.

4. Presents accurate information to students concerning alcohol/drug abuse.

6 Recognizes the overt physical and behavioral indicators of child abuse and neglect and knows the rights and responsibilities regarding reporting and how to interact appropriately with a child after a report has been made.

1. Recognizes physical, mental, emotional, and social behavioral indicators of child abuse and neglect.

2. Knows the rights and responsibilities of all parties involved and the procedure for reporting abuse/neglect incidents.

3. Knows how to interact appropriately based on the child's needs after a child abuse/neglect report has been made.

7 Formulates a standard for student behavior in the classroom.

1. Identifies approved safety procedures, student characteristics, and socially accepted norms (such as mutual respect, consideration of others, courtesy) and incorporates them into a standard for student behavior in the classroom.

2. States expectations about student conduct, giving rules or developing them with students, and illustrating rules for clarification. 
3. Identifies and incorporates local and state policies into a standard for student behavior in the classroom.

4. Implements rules and maintains a standard of conduct.

5. Monitors compliance and non-compliance with classroom rules and provides consequences to increase appropriate and decrease inappropriate behaviors.

8 Deals with misconduct, interruptions, intrusions, and digressions in ways that promote instructional momentum.

1. Recognizes factors, in and out of school, which contribute to student misconduct.

2. Correctly identifies the students who misbehave and gives clear statements concerning the violation and the expectation without overdwelling, expressing roughness, and creating undue emotional tension.

3. Attends to two tasks at the same time without affecting ongoing instruction.

4. Uses appropriate verbal and/or non-verbal techniques for reinforcing and modifying student behavior.

5. Identifies and uses parental assistance and/or school and community resources to modify student behavior.

9 Determines the entry level knowledge and/or skills of students for a given set of instructional objectives using diagnostic tests, teacher observation, and student records.

1. Selects an appropriate method for assessing prerequisite knowledge, understandings, and/or skills.

2. Selects or constructs an appropriate evaluation instrument to assist in assessment of student learning needs.

3. Makes effective use of classroom observation techniques to assist in assessment of student learning needs.

4. Makes appropriate use of information from student records to assist in assessment of student learning needs.

5. Interprets results obtained from diagnostic tests, teacher observation, and information from student records to assist in diagnosis of student learning needs and to guide instruction.

10 Identifies long-range goals for a given subject area.

1. Formulates subject area goals consistent with state and district goals.

2. Identifies long-range goals appropriate to student needs.

11 Constructs and sequences related short-range objectives for a given subject area.

1. Identifies knowledge, skills, and attitudes to be attained for a subject area.

2. Constructs or adapts short-range objectives for identified knowledge, skills, and attitudes. 
3. Organizes and sequences short-range objectives consistent with commonly accepted principles of learning.

4. Organizes content into sequential steps consistent with identified short-range objectives.

5. Considers individual differences in determining short-range objectives.

12 Selects, adapts, and/or develops instructional materials for a given set of instructional objectives and student learning needs.

1. Selects materials based on instructional objectives and student learning needs and readiness levels.

2. Adapts materials to assist students in mastering objectives.

3. Determines materials to be developed based upon existing resources and student needs.

4. Désigns and/or selects materials based on instructional objectives, individual student needs, and available resources.

5. Knows and observes current copyright laws.

6. Uses a variety of materials and media based upon objectives, student needs, and available resources.

13 Selects/develops and sequences learning activities that are appropriate to instructional objectives and student needs.

1. Identifies and implements learning activities which are consistent with basic principles of human growth and development, giving consideration to various individual learning styles.

2. Selects or develops activities that recognize conditions that affect learning.

3. Selects or develops appropriate learning activities to achieve objective(s).

4. Combines appropriate learning activities into an instructional sequence.

14 Uses class time efficiently.

1. Begins classwork promptly.

2. Focuses teacher and student talk on academic subject matter.

3. Manages transitions from one activity to another in a systematic, academically oriented way.

4. Establishes and enforces rules to be followed by students who are tardy, are without supplies, or who must enter or leave the room during instruction.

5. Plans activities for students who complete classwork early.

6. Establishes routines for preparation, distribution, and collection of materials and movement of students in the classroom.

15 Communicates effectively using verbal and non-verbal skills.

1. Organizes, sequences, and presents ideas/materials using the basic principles of English at a level appropriate to students.

2. Listens effectively to messages, identifies relevant/irrelevant information, draws inferences, and summarizes the message(s). 
3. In oral presentations, modulates voice quality and level to add interest and to stress important information.

4. In written presentations, (e.g., boardwork, letters to parents, etc.) applies basic mechanics of writing, spelling, capitalization, and punctuation.

5. Uses non-verbal communications to enhance student action and student performance.

6. Utilizes effective techniques for emphasizing important points.

16 Creates and maintains academic focus by using verbal, non-verbal, and/or visual motivational devices.

1. Relates instructional objectives and activities to interests, feelings, capabilities, and experiences of students.

2. Informs students about objectives, subsequent learning tasks, and performance expectations.

3. Modifies instructional strategies during learning activities based on student responses and needs.

4. Uses reinforcement techniques to maintain on-task behavior and promote student motivation.

5. Uses media to secure interest and maintain academic focus.

6. Uses student ideas, talents, and products to secure interest and maintain attention.

7. Directs student attention by use of verbal and non-verbal signals and cues.

17 Presents forms of knowledge such as concepts, laws, and law-like principles, academic rules, and value knowledge.

1. Teaches concepts by providing or inducing definitions, examples, non-examples, and attributes, and by distinguishing related concepts.

2. Teaches laws or law-like principles by analyzing cause and effect, stating the causal principle/law, using linking words to connect effect/s to cause/s, and by providing for application of law or principle.

3. States academic rules, describes/analyzes the situation in which the rule applies, and provides for practice in applying the rule.

4. Teaches value knowledge by stating and exploring the value question, developing criteria of judgment, assembling facts, and testing the value judgment.

18 Presents directions appropriate for carrying out an instructional activity.

1. Informs students of objectives, assessments, and performance standards.

2. Informs students of the sequence and nature of learning activities to achieve the objectives.

3. Informs students of materials needed for a learning activity and explains their use.

4. Determines if students understand directions. 
19 Stimulates and directs student thinking and checks student comprehension through appropriate questioning techniques.

1. Orients students to classwork and provides appropriate transition statements.

2. Asks low order and high order questions effectively to stimulate and direct student thinking and learning.

20 Provides appropriate practice to promote learning and retention.

1. Varies the structure, duration, and nature of practice activities, based upon complexity of material and ability of the learner.

2. Reinforces retention of specific information or skill by directing students to respond individually and/or together.

3. Provides a variety of activities for repetitive practice to promote learning and retention.

4. Circulates and assists students during seatwork to check comprehension and provide assistance.

5. Provides massed and distributed practice activities to promote longterm retention.

21 Relates to students' verbal communications in ways that encourage participation and maintain academic focus.

1. Shows acceptance and value of student responses by seeking clarification or elaboration, or uses a student's comment to foster or redirect further discussion.

2. Ignores or redirects digressions without devaluing student response.

22 Uses feedback procedures that give information to students about the appropriateness of their response/s.

1. Provides clear, unequivocal, feedback to students indicating that a response is correct or incorrect.

2. Makes specific statements that indicate what was praiseworthy about, or the implications of, a student's response.

3. Corrects students' errors by giving a correction, or assists students in correcting their own errors by providing an explanation, additional information, or asking additional questions.

23 Conducts reviews of subject matter.

1. Involves students in a summary or rehearsal of previous lesson/s at the beginning of a new lesson.

2. Recaps significant points of a discussion before moving to a new topic, aspect or problem, or engages students in doing so.

3. Engages students in an end-of-lesson recap, summary, or review of subject matter.

4. Engages students in weekly and monthly reviews to ensure long-term retention. 
24 Constructs or assembles classroom tests and tasks to measure student achievement of objectives.

1. Identifies, selects, and constructs test items and tasks that appropriately assess mastery of an objective.

2. Constructs items and tests according to recognized criteria.

3. Identifies criteria for standards of performance.

4. Evaluates and revises tests on the basis of content validity, reliability, and student responses.

25 Establishes a testing environment in which students can validly demonstrate their knowledge and skills and receive adequate information about the quality of their test performance.

1. Demonstrates effective procedures for orienting students to tests, specifying test content, and instructing students in test-taking prior to administration of a test.

2. Administers tests in ways to reduce debilitating anxiety, discourage cheating, and control potential distractions.

3. Provides feedback on test results in a manner which expresses approval and gives information for correcting errors in understanding.

26 Utilizes an effective system for maintaining records of student and class progress.

1. Constructs a system for recording the progress of individual students and the total class.

2. Identifies effective methods for reporting individual student and class progress.

3. Demonstrates knowledge of the contents and procedures for maintaining student permanent records.

4. Demonstrates knowledge of the laws and policies governing the content and use of student records.

27 Uses computers in education.

1. Recognizes proper operational procedures for computers.

2. Identifies major components and their functions of a computer system commonly used in an educational setting.

3. Recognizes criteria for selecting software for use in an instructional setting.

4. Recognizes the ethical and legal impacts and consequences of a computerized society.

5. Identifies appropriate school and classroom management applications of computers.

6. Selects methods of integrating computers in instruction. 
APPENDIX C

Professional Orientation Program (POP) Survey 


\section{Dear POP Participant:}

Attached is a very important survey that we urge you to take about 45 minutes to complete. It was designed collaboratively by representatives from the teacher preparation programs throughout the State of Florida, with the assistance of the Professional Orientation Program Coordinators, the Department of Education, and the Florida Education Standards Commission. Your responses to this survey will be analyzed and given to the teacher preparation program from which you graduated (if it has approved programs in Florida) and to your district POP Coordinator. The survey is also being mailed to Florida graduates who are now out-of-State.

The information we will gain from this survey is extremely important to us, as we hope to refine our programs based on your feedback. Your comments on the last page are of particular interest to us. so we hope you will take a little extra time to provide them to us. If you want them to be anonymous, simply provide them on a separate piece of paper that identifies your institution and return them with your surve: to your district POP Coordinator, who will then combine them with all of the other surveys for computer scanning. Because of the volume of surveys. you can be certain that your anonymity will be preserved.

\section{Also. don't forget to use a number two pencil.}

We know how busy you are and regret any imposition this survey may cause you. We sincerly appreciate your willingness to support your alma mater by completion of this surves. and we thank you on their behalf.

Please return the sure: to your POP Coordinator by Februar: 1. 1993.

Sincerely.

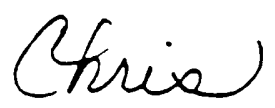

Christine A. Vacha, Chairperson

Chairperson, Professional Orientation Program Advisory Committee

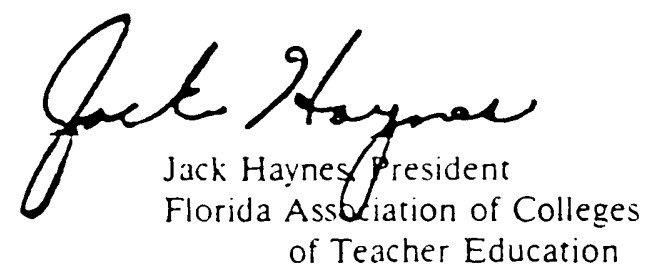


1. Code your soclal Security Number in the above grtd(opelonal). Section I - General Information

2. Gender: Male Female

3. Race: African-American

Anglo

Asian

Lat1no

Native Amertcan

other

4. Are you legally dieabled: yes no

5. Coliege/university from which you graduated:

6. Was the snotitution froo which you graduated 1n Fiorita? yeo no

7. Coliege/valversity at which you did your inal intarnghip (1f alfserent from 45 above):

8. In what year did you graduate:

9. What 10 the higheat degree you have completed?

aachelors

Masters

Special1sts

Doctorate

:0. Dave you begun wark on another degree? Yes, in Education

Yeo, but net is Eucation

Yo, but plan to to so within the next two years

ro, presently have no pians to work on an advanced degree

11. Did you complete a program leading to certilication? Yes No

12. If you completed a program leading to certiflcation, what was your major? crid your angwer at the top of this page.

100 Art Educatior:

103 Drama/Theacer Education

106 Engl1en Educat1on

109 Guldance/Counseiling

112 Induatrlal Arts

115 Phyolcal Education

118 Science/Bealth Education

121 Vocational Education

13. What type of position do you presently, have? Feacher

101 Bustrese Education

104 Early Calidhood

107 Forelgn Language Educat:on

210 dealth Education

113 Mathematics Educat:on

::5 Reading Education

119 Social Selence Education

122 other i02 Computer Education

105 Elementary Education

108 Gifred Education

$:: 1$ Howe Economica

114 Music Education

il7 School Psychology

220 Spectal/Exceptiona: Education

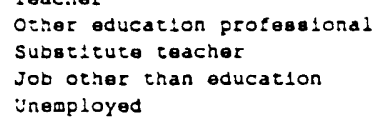

14. If you are Nor currently employed in ectcatlon, please indicate why you are not employed in this area:

No position availabie where I live.

Applled for education postion la everal locattone, but none avallable

ine present work better

wanted to work toward a higher degree

other, specify

If you are not currently employed as an educational professional, please go to Section II.

15. Nre you currenty teaching in Florlda?

YeB No

16. : t you are teaching in Florlda, in what school district are you employed?

17. If you aro not teaching in Florlda, in what scate and school diatrict are you employed?

18. In what type of echool are you working?

Elementary

Middle (Junior algh School)

aigh School

Pro-echool

vocational/technical school

Post-secondary

Other 


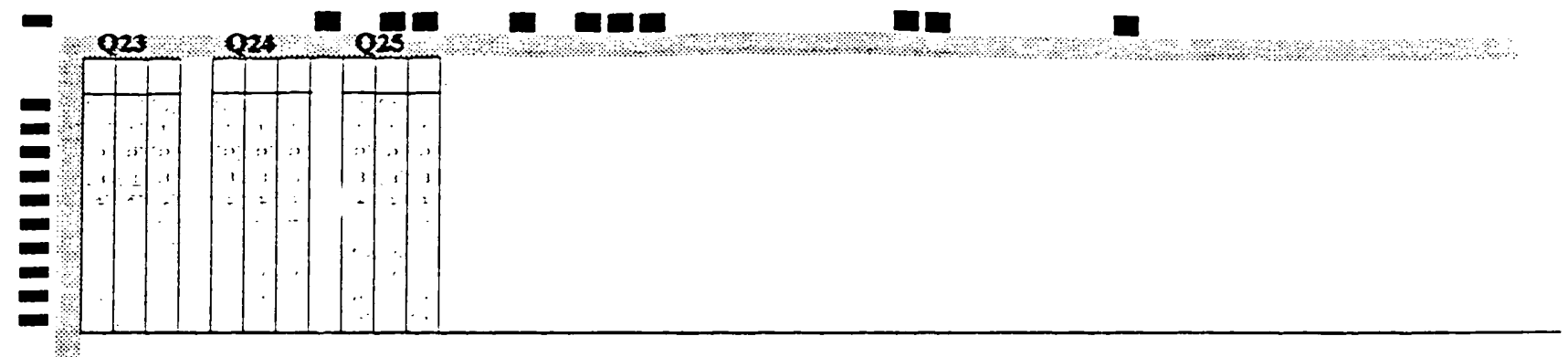

19. Is the echool public or private? Publle "Private

20. Which of the following best describes the community in which this echool is located:

$$
\text { Rural Suburban Urban }
$$

21. What perceatage of your echool' etudente qualify for free or reduced luneh?

over 75 51-75* 26-508 0-258

22. What 10 your plorlda school code number?

Use the following codes to answer questions 23 thra 25 . Place your answer in the appropriate grid at the top of this page.

100 NT Bducat10

101 Businees Education

103 Drama/Theater Bducation 104 Barly Chlldhood

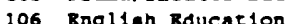

109 Guldance/Counseling

112 Induetrial Arte

115 Phyelcal Education

105 Bjamantary Bducat

107 Porelgn Language Bducation 108 G1fted Bducat10a

110 Bealth Bducation 111 Bamo Bconomica

113 Mathematice Bducation 114 Music Bducation

Bclence/Bealth Bducation 119 Social Sclence Bducation

117 School paychology

121 Vocational Bducation 122 other

23. What 1s the broad fleld of certiflcation in which you hold a temporary certiflcate?

(If you have a econd area, please lndicate that area in the next queation.)

24. If you have a second broad fleld of certiflcation, 1n what area le that eecond certiflcation?

25. In which of the broad fleld areas of certiflcation are you placed for moet of your teachlng aselgnmont?

26. Dose your current teaching aselgnment 1nclude clasees from wore than one of the broed fleld areas?

If so, 11st the areas.

Yes

no

27. Are you now, or have you been, in an Altqrate Ieacher Preparation Program?

Yoe .... No

28. It you are teaching 1 a plorlda, how did you plad out about teaching vacancles? (Check all that apply).

Great Plorida Teach-In

office of Teacher Rocrultment and Retention

Contacts made from etudent teaching experience

..., College/Univera1ty eponaorod job la1r

- Assistance from ataf in your teacher preparation inetitution

Dietrict recrustment activitioe

Belf-1nftlated contacta

... Other

29. Are you enrolled in any add-on certifleatlon programa?

Yas, through univeratty course work

Yos, through dietrict laservice progreme.

No 


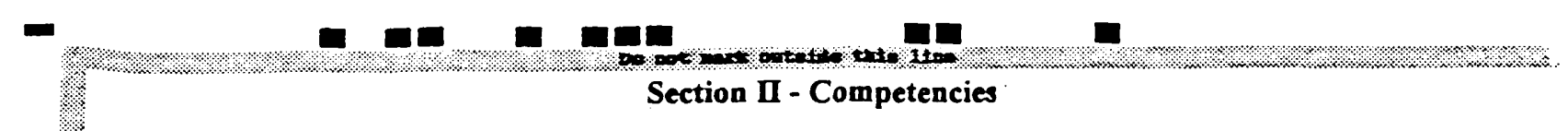

Recognizing that some competencies are used more often then others, rate the degree to which you feit PREPARED at graduation for your teaching responsiblities and the initial SUCCESS you are now experiencing in your professional position. If you ARE NOT currently workding as an education professional, only rate your preparedness. Please use the following scales:

\section{PREPAREDNESS}

$4=$ Very well prepared

$3=$ Moderately well prepared

$\mathbf{2}=$ Onty minimally prepared

1 = Not prepared at all

NA $=$ Not applicable

\section{SUCCESS}

$4=$ Perform very successfully whenever appropriate

$3=$ Perform moderately weil

2 = Have some difficulty performing

1 = Unable to perform

DK = No opportunity to apply/don't know

NA $=$ Not applicable

1. Match 1netructional etrategtee to etudent learner needs.

PREPARBDKRSS:
SUCCBSB:

2. Neslet students in developing positive self-concepts, values, attitudes, and bellefa.

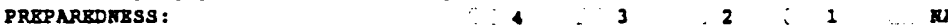

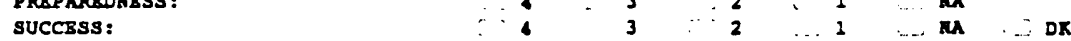

3. Neslet studente In appreclatiag and respecting persone froll varlous ethnic, cultural, 11nguletic, and econonic groupe.

PRSPARSDKBSS:
SUCCBSS:

4. Arrange claseroce furniture, oqu1pment, and lnatructional alde to facllitate teachlag, loarning, and aafoty.

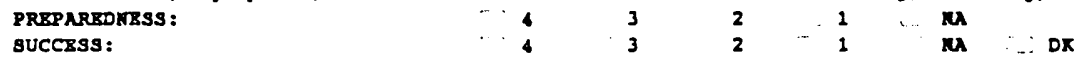

5. Manage sttuations 1nvolving eovere emotional etrese.

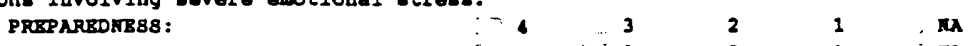

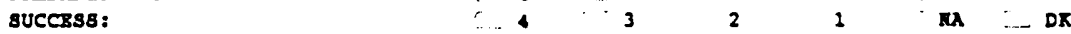

6. Manage eltuatione lavolving elcohol and drug abues. PRKPARKDKBSS: 8uccrss:

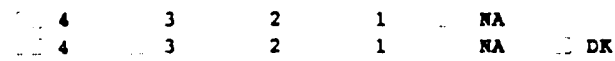

7. Manage eltuations lavolving ctild abuse and/or neglect.

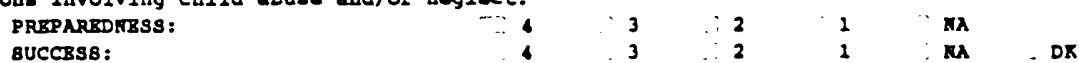

8. Implement ecbool rules and malntaln a etandard of claseroom conduct. PPBPARKDNBSS :
SUCCBSS:

9. Use verbel/non-verbel technlques, parente, and school/communlty resourcen to relnforce or modify atudent behaviors. PRBPAREDERs:

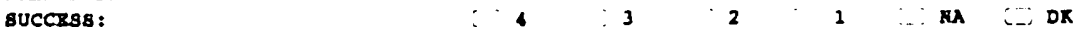

10. Dotermine etudente' entry lovel knowlodge/extllo uelog dlagnostic tests, toacher observation, and etudent rocords. PREPPARSDNBSS: succrss:

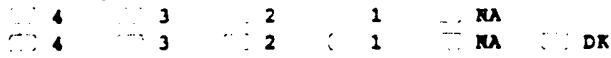

11. Pormulate long-range goele that are both consletent witb atete and district goels and appropriate to atudent neede. PRBPARBDKRSB: succos8:

12. Construct and exquence short-range objectiven for a given subject area. PRBPARBDKB88: Buccsss:

13. Uee a vartety of mater1ale and medts based upon currtcular objectives, etudent neede, ard avallable resources. PREPARBDHESS :

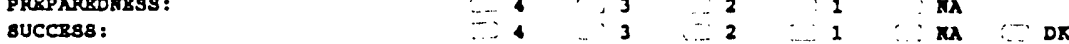

14. Belect/develop and eequence learning activitiee appropriate to lnetructional object1ves and etudent learnlag neede. PREPAREDKBS8: 8UCCR88:

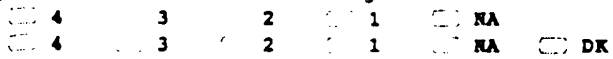

15. Une clase tine efflciently. PRBPARBDNB8S: suCCRs8:

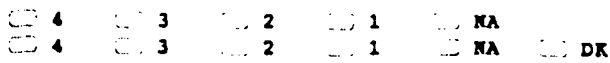




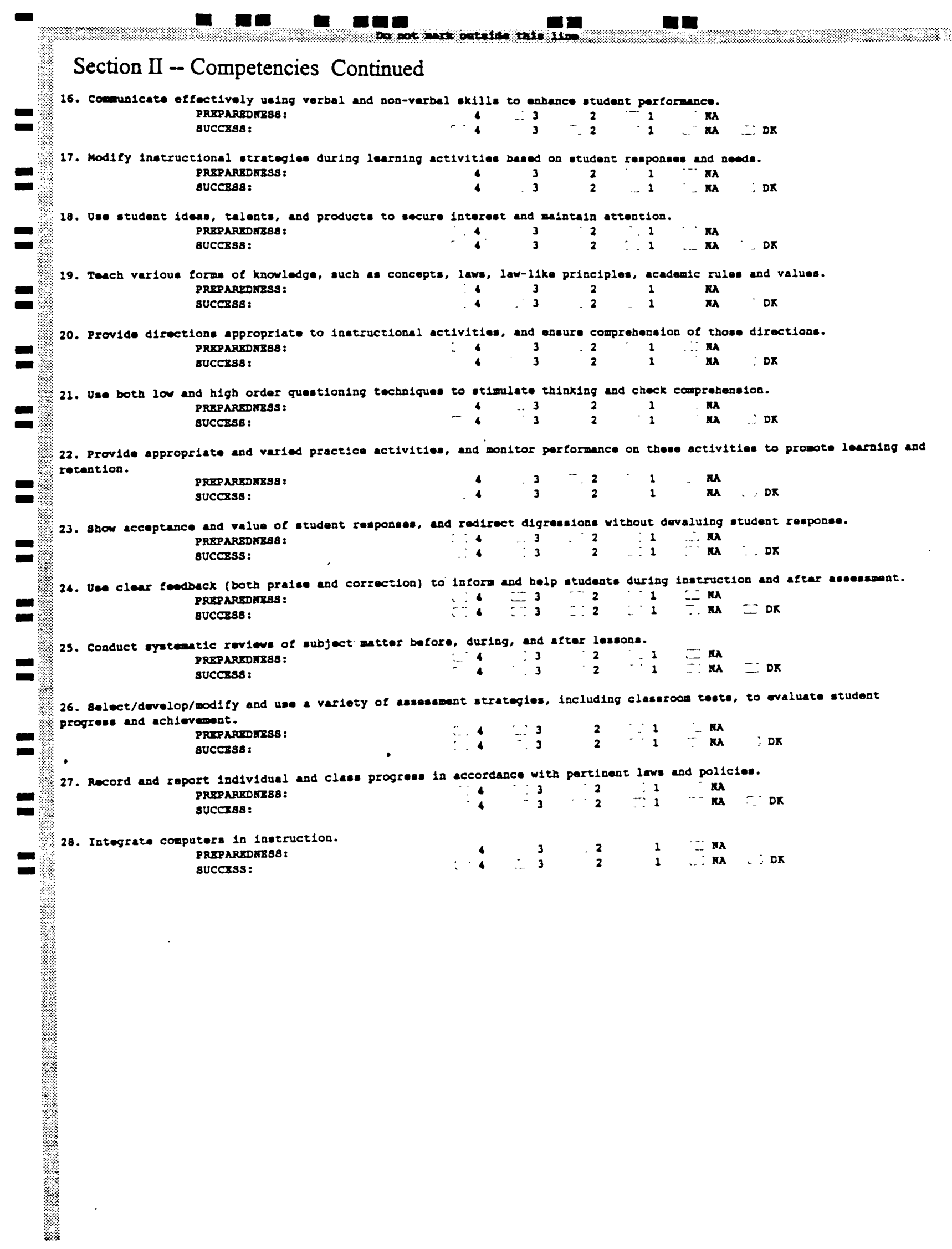




\section{Section IV - Perspectives on the Profession}

1. What are your long range plana as an education profeanional?

Iatend to continue undecided at prosent

2. To what extent do you neod follow-up support from the teacher preparatloa program from whlch you graduated?
To a great extent
some axtent
A $11 t t 10$
Not at all

3. Please epecify the type and content of aseletance you would like:

4. How long have you been in the Profesalonal ortentation Program?

$$
\text { Lose than } 90 \text { days Between } 90 \text { and } 180 \text { days. More than } 180 \text { days }
$$

5. Please rate the adequacy of the support you are recelving from your bullding level adminiatrator in your Proseselonal orjentation Progras.

More than adequate Adequate Lees than adequate Inadequate: Not enrolled

6. Pleane rate the adequacy of the eupport you are recelving from your peer teacher in your Profoselonal orientation Program.

More than adequate Adequate Lese than adequate. Inadequate Not enrolled

7. Pleane rate the adequacy of the support you are recelving from your otber profeasional educator in your Profenelobal Orientation Program.
- More than adequate.... Adequate
Lees than adequate - Inadequate
Not enrolled

8. What would you identfy as the most etreseful aspect of your beginnlog teaching experiences?

Based on your teaching experience, how satisified are you with each of the following aspects of teaching. Use the following scale:

$$
\text { VS = Very satisified } \quad S S=\text { Somewhat satisified } \quad S D=\text { Somewhat dissatisified } \quad V D=\text { Very dissatisified }
$$

9. class 120 .

10. The avallability of resources and materiale/oquipment for the classroom.

11. The achool'e phyelcal environment (safoty, malntenance, cloanlinese, appearance).

12. Support, ecceptance, or recognttion from colleagues.

13. The work load (assignent, perspectives, aumber/nature of students, otc.)

14. The methode of teacher assossment and porformance ovaluation.

15. Autonomy within the claseroom.

16. Opportun1ties to be informed and interact with other professionale.

17. Student motivation to learn.

18. Btudent disclpline and behavior.

19. The protesetonalien of colleagues.

20. Opportuntty for continuing profeselonal growth and study.

21. Cowmity attitude and eupport for the teaching profession.

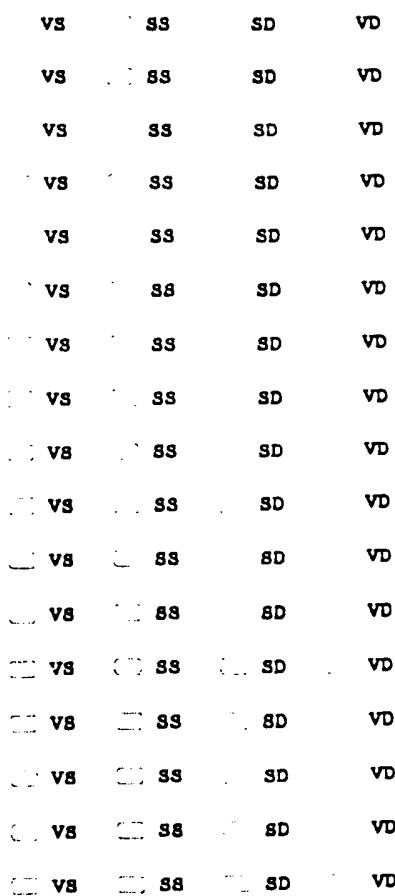

25. Aeeletance avallable lor deallag with etudente with speclal noods.

v8 $38 \quad$ so

vo 


\section{Section V - Comments}

Please write your overall comments on your teacher education program.

Strengths of your Teacher Education Program:

Suggestions for improving your Teacher Education Program:

Suggestions for improving your Professional Orientation Program:

Add additional sheets if necessary. Thank you. 
APPENDIX D

Florida School Districts 
$\mathrm{n}=1999$

General Information

School district in which employed

Percent

Alachua

$2 \%$

Baker

$0 \%$

Bay

$3 \%$

Bradford

$0 \%$

Brevard

$4 \%$

Broward

$12 \%$

Calhoun

$0 \%$

Charlotte

$1 \%$

Citrus

$0 \%$

Clay

$3 \%$

Collier

$0 \%$

Columbia

$1 \%$

Dade

$6 \%$

DeSoto

$0 \%$

Dixie

$0 \%$

Duval

$3 \%$

Escambia

$1 \%$

Flagler

$1 \%$

Franklin

$0 \%$

Gadsden

$0 \%$

Gilchrist

$0 \%$

Glades

$0 \%$

Gulf

$0 \%$

Hamilton

$1 \%$

Hardee

$1 \%$

Hendry

$1 \%$

Hernando

$1 \%$

Highlands

$0 \%$

Hillsborough

$9 \%$

Holmes

$0 \%$

Indian River

$1 \%$

Jackson

$0 \%$

Jerrerson

$1 \%$

Lafayette

$1 \%$

Lake

$1 \%$

Lee

$1 \%$

Leon

$3 \%$

Levy

$1 \%$

Liberty

$0 \%$

Madison

$0 \%$

Manatee

$1 \%$ 
Monroe

$1 \%$

Nasau

$0 \%$

Okaloosa

$2 \%$

Okeechobee

$1 \%$

Orange

$3 \%$

Oceola

$2 \%$

Palm Beach

$7 \%$

Pasco

$3 \%$

Pinellas

Polk

$2 \%$

$2 \%$

Putman

$1 \%$

St. John

$1 \%$

St. Lucie

$0 \%$

Santa Rosa

$2 \%$

Sarasota

$1 \%$

Seminole

$0 \%$

Sumter

$1 \%$

Swanee

$0 \%$

Taylor

$0 \%$

-Union

$0 \%$

Volusia

$0 \%$

Wakulla

$0 \%$

Walton

$0 \%$

Washington

$0 \%$

D. Of St. Pete

$0 \%$ 


\section{APPENDIX E}

Professional Orientation Program (POP) Current Status Report 


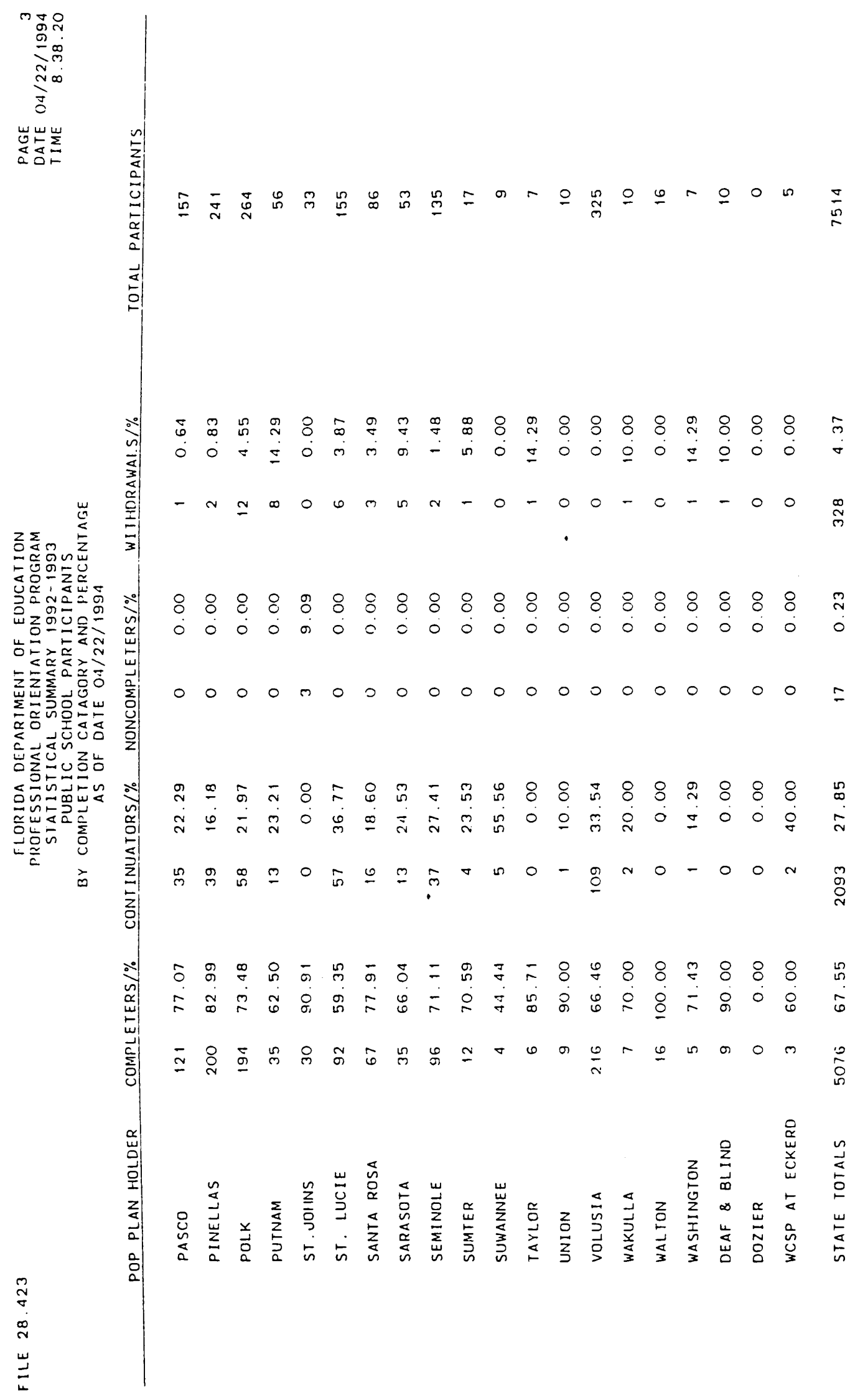




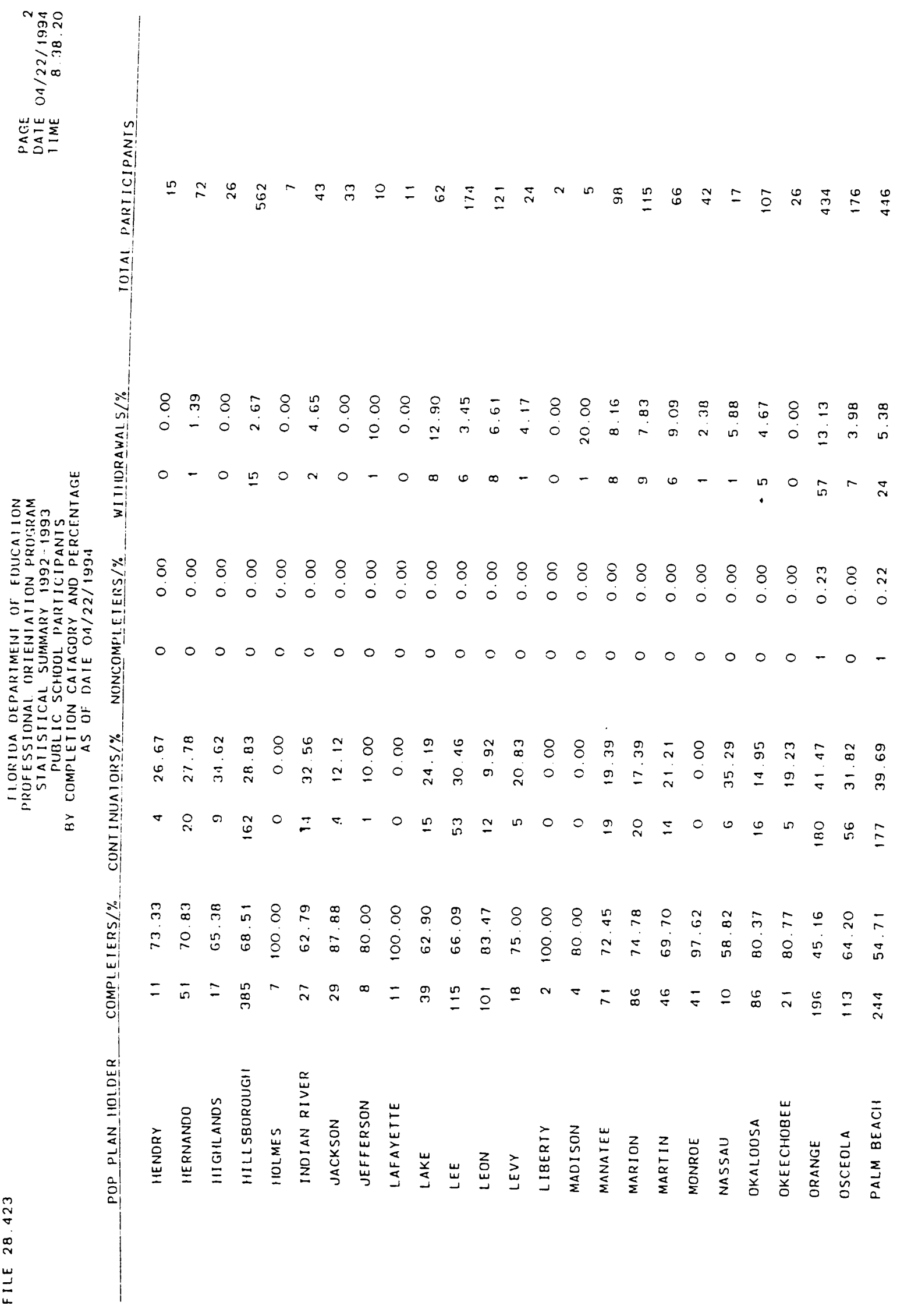




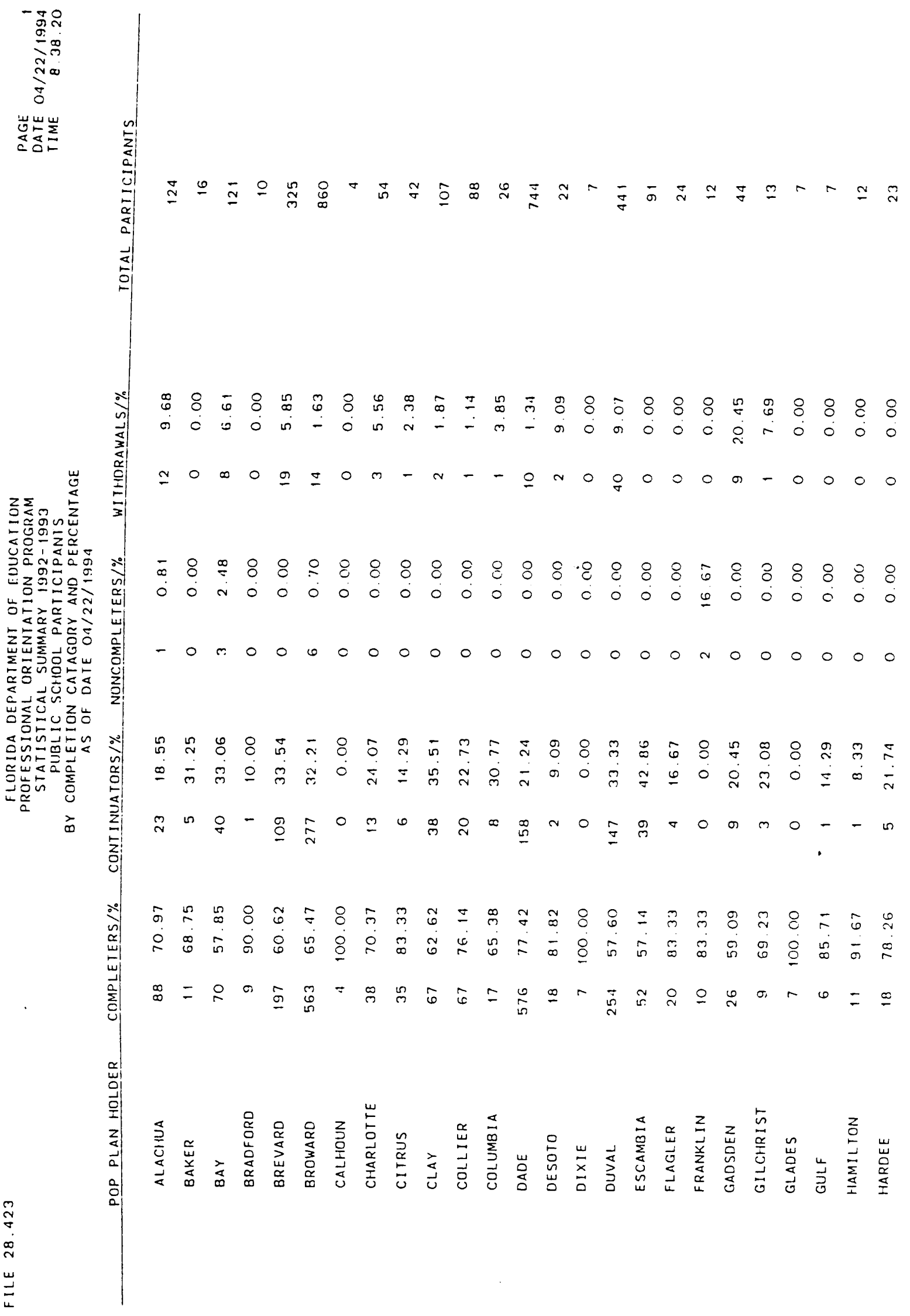




\section{APPENDIX F}

Florida Graduating Institutions 
Flagler College

florida A\&M University

Florida Atlantic U

florida Institute of Technology

florida International University

florida Memorial College

Florida Southern College

Florida State $U$

Jacksonville University

Hova University

Palm Beach Atlantic

Rollins

Saint Leo College

St. Thomas $U$

Southeastern Col lege

Stetson University

$U$ of Central Florida

University of Florida

University of Miami

$0 x$

$0 x$

$0 x$

$1 x$

$1 \%$

$5 x$

$0 \%$

$4 \%$

$0 x$

$2 x$

$10 \%$

$1 \%$

$5 \%$

$0 \%$

$0 \%$

$1 x$

$0 x$

$0 \%$

$1 \%$

$9 \%$

$7 x$

$1 x$

$4 x$

$U$ of South Florida $12 \%$

$U$ of Tampe $1 \%$

$U$ of West Florida $3 x$

Warner Southern $1 \%$

out of State $27 \%$

other Florida Institution $1 \%$ 


\section{VITA}

January 20,1950

1971

1973

$1971-1973$

1973-1977

1977-1979

1979-1984

1984-1988

1988-1989

1989-1995
Born, Havana, Cuba

B.A., Elementary Education and Early Childhood University of Miami

Miami, Florida

M.Ed. Administration and Supervision

University of Miami

Miami, Florida

Elementary Teacher

Dade County Public Schools

Miami, Florida

Teacher on Special Assignment

Dade County Public Schools

Miami, Florida

Educational Specialist

Dade County Public Schools

Miami, Florida

Assistant Principal

Dade County Public Schools

Miami, Florida

Executive Director, Community Relations

Florida International University

Miami, Florida

Associate Vice President/Acting Vice President University Relations \& Development

Florida International University

Miami, Florida

Associate Dean, College of Education

Florida International University

Miami, Florida 